\title{
LAS ÚLTIMAS IMPORTACIONES ROMANAS DE CERÁMICA EN EL ESTE DE HISPANIA TARRACONENSIS: UNA APROXIMACIÓN
}

\author{
THE LAST ROMAN CERAMIC IMPORTS IN EASTERN HISPANIA TARRACONENSIS: AN APPROACH
}

\author{
RAMÓN JÁRREGA DOMÍNGUEZ*
}

\begin{abstract}
Resumen: En los últimos años, se han publicado diversos estudios que han permitido tener un buen conocimiento sobre las importaciones (terra sigillata, ánforas, lucernas) en la costa de la antigua Hispania Tarraconensis en época romana tardía. Este conocimiento, concerniente a los contextos urbanos (las ciudades antiguas de Barcino, Tarraco y otras) y los establecimientos rurales, permite determinar las tendencias de las importaciones y la economía en esta área entre los siglos IV y finales del VI e inicios del VII d.C. El aumento de datos necesita una interpretación, orientada hacia la determinación de las tendencias del comercio y las importaciones, y la relación económica entre la ciudad y el campo en la actual Cataluña en la Antigüedad Tardía. Con esta contribución, esperamos poder colaborar en la elaboración de un trabajo interpretativo de síntesis sobre estos aspectos.
\end{abstract}

Palabras claves: Cerámica, Comercio, Hispania Tarraconensis, Cataluña, Antigüedad Tardía.

\section{INTRODUCCIÓN}

El Noreste de la Península Ibérica tiene un interés especial para el estudio del comercio antiguo, dada su posición en el ángulo occidental del Mediterráneo y su ubicación en encrucijada entre el Este y el Oeste del mismo. Esta posición permite estudiar la interacción de

\footnotetext{
* Institut Català d'Arqueologia Clàssica, plaça. Rovellat $\mathrm{s} / \mathrm{n}$. 43003-Tarragona. Correo-e: rjarrega@icac.cat
}

\begin{abstract}
Recently had been published some studies that had provided a good knowledge about the imports of pottery (terra sigillata, amphoras, lamps) in the coast of the ancient Hispania Tarraconensis in the the Later Roman times. This knowledge, concerning the urban contexts (the ancient towns of Barcino, Tarraco and others) and the rural establishments, allows us to determine the tendencies of the imports and the economy in this area between the IVth and VIIth centuries A.D.

The increase of data needs an interpretation, oriented towards the determination of the tendencies of the commerce and the imports, and the economic relationship between town and country in the area of present Catalonia in Late Antiquity. With this contribution, we hope to collaborate to the elaboration of an interpretative synthesis about these aspects.

Keywords: Pottery, Trade, Hispania Tarraconensis, Catalonia, Late Antiquity.
\end{abstract}

los productos itálicos, africanos, hispánicos y gálicos en dirección Norte-Sur, así como valorar la incidencia en esta zona de otra corriente comercial más distante, procedente concretamente del Este del Mediterráneo.

El propósito de este trabajo es realizar una aproximación general a la evolución del comercio en el período tardoantiguo en la zona costera de la antigua provincia Tarraconensis, a partir del estudio de la cerámica. Considerando la posibilidad de efectuar una aproximación evolutiva, dividiremos esta síntesis a partir de bloques cronológicos. 


\section{PROBLEMÁTICA DE LA INVESTIGACIÓN}

Al abordar el estudio de la circulación de las mercancías, y en concreto de las cerámicas, tenemos que estudiar también el papel de los puertos como centro distribuidor: Estos puertos corresponden a las ciudades de Emporiae (a pesar de los cambios y la decadencia urbanística de la ciudad, hubo una continuidad con nuevos parámetros, con el núcleo habitado de Sant Martí d'Empúries), Barcino, Tarraco y (aunque muy poco conocida), Dertosa. Existe también el problema de los posibles puertos de Iluro y Baetulo, muy desconocidos (especialmente el primero), pero que debieron funcionar también como punto de descarga de mercancías ( $c f$. Izquierdo 1997 y 2009).

Existe un claro desconocimiento (tanto para el Alto Imperio como para el período tardoantiguo) del "status" jurídico de los puertos: la legislación romana recoge diversas modalidades (portus, stationes) y no sabemos exactamente cómo definir los que acabamos de mencionar. Probablemente los de Tarraco, Barcino y Dertosa deberían ser verdaderos portus, pudiendo ser quizás los de Baetulo e Iluro simples stationes. Sin embargo, las transacciones comerciales (y por lo tanto, los productos estudiados) deberían pasar sin duda por ellos.

Desgraciadamente, no conocemos ningún contexto portuario como el de Massilia, en el cual, gracias a los estudios de Bonifay y Piéri (Bonifay 1983 y 1986, Bonifay y Piéri 1995) ha sido posible estudiar una interesantísima seriación estratigráfica que ha permitido profundizar en el conocimiento de las cerámicas tardoantiguas de importación, especialmente las ánforas. El puerto de Barcino presentan datos interesantes para el siglo I, con una importante relación con las alfarerías anfóricas que servían para envasar el vino layetano. Del puerto de Tarraco conocemos algunas estructuras arquitectónicas que podemos interpretar como parte de los horrea portuarios (Pociña y Remolà 2001, Pérez 2007: 65-82), pero no existen datos de época tardoantigua; sin embargo, se tiene que poner en relación con el barrio portuario el importante complejo funerario y cultual que se ha documentado junto al río Francolí (Del Amo 1979 y 1981, Keay 1984, López 2006), en el cual se han encontrado en abundancia ánforas reutilizadas en los enterramientos.

De forma general, nos hallamos ante un problema de falta de contextos, que nos podrían haber permitido efectuar estadísticas fiables. O bien no hay contextos o, cuando éstos existen, a menudo son conjuntos de materiales demasiados esporádicos. Tampoco se ha estudiado ningún derelicto tardoantiguo, aunque se han localizado hallazgos aislados en la costa cercana a Tarragona (Pérez 2007: 219-220, 259-260), por lo cual nos tenemos que centrar en los datos proporcionados por los yacimientos terrestres. Sin embargo, hay que tener en cuenta que para este período los derelictos son muy esporádicos en general en el Mediterráneo occidental (cf. Parker 1992).

Es interesante poner de relieve que, gracias a la costumbre de la inhumación en ánforas que se extendió en época tardoantiga, las necrópolis (especialmente las urbanas) han sido las principales fuentes de información para el conocimiento de la circulación de las ánforas en Cataluña durante la Antigüedad Tardía. Destacan las necrópolis de Ampurias, lo cual por sí solo ya permitiría matizar la supuesta decadencia de esta ciudad (cf. Nolla 1993, Nolla y Sagrera 1995, Llinàs 1997), las de Barcelona, tanto las de la necrópolis de la plaza del Rey (Pascual 1963, Keay 1984, Járrega 2005a) como la de Santa Maria del Mar (Ribas 1967, 1968 y 1977, estudio de estos materiales en Keay 1984) y las de Tarragona, donde los materiales de la necrópolis del Francolí y otros lugares próximos fueron publicados por Serra Vilaró (1927, 1929 y 1930), Del Amo (1979) y Sánchez (1971-72), y estudiados por Keay (1984) y Remolà (2000).

Eso ha comportado un buen estado de conservación de las piezas y la posibilidad de estudiarlas y plantear la realización de series tipológicas, lo cual fue bien aprovechado por Keay (1984) para llevar a cabo su fundamental estudio de conjunto. Por lo tanto, los contextos catalanes han permitido contar con un importante punto de partida para el estudio de las ánforas tardoantiguas y ha sido la base de algunas tipologías, como las formas Almagro 51 y 54 (definidas a partir de los materiales de las necrópolis de Ampurias), y las aportaciones tipológicas de Keay (especialmente las formas 25, 35, $61 \mathrm{y}$ 62 ), a partir de los contextos antes mencionados.

La gran dificultad que presenta el estudio de las ánforas de esta época es el desconocimiento generalizado de su contenido, que sería básico para el estudio del comercio. Tradicionalmente se había supuesto que las ánforas africanas servían para transportar el aceite que mencionan las fuentes escritas, pero la realidad arqueológica permite ponerlo en duda, especialmente por la presencia de revestimientos interiores resinosos (en las ánforas Africana $2 \mathrm{~A}$, así como en algunos casos de otras formas) que es imposible que se puedan relacionar con la comercialización del aceite (Bonifay 2004: 111, 463-467, 470). Ello plantea una dificultad añadida para el estudio del comercio tardoantiguo, en comparación con el de época altoimperial. 


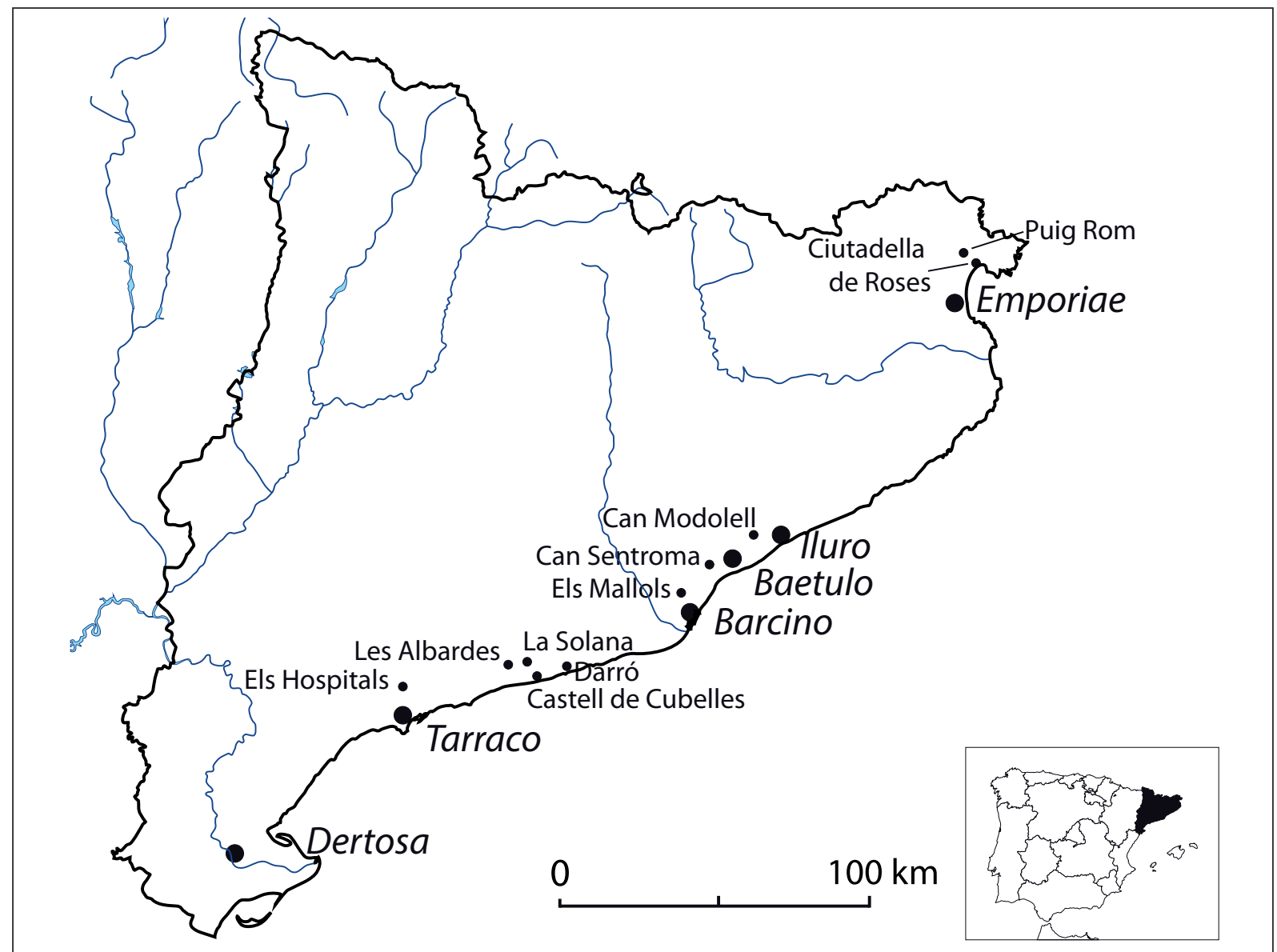

Figura 1. Situación de los principales contextos arqueológicos de época tardoantigua en Cataluña.

Menos problemas presentan las ánforas béticas y lusitanas (Dressel 23, Almagro 51 A/B-Keay 19 y Almagro $51 \mathrm{C}$ - Keay 23), ya que las primeras son sin duda olearias, y en lo que se refiere a las ánforas Keay 19 y 23 tenemos que suponer que mayoritariamente transportaban productos de salsamenta de la zona del Algarve y del bajo curso del río Tajo (Alarcão y Mayet 1990, Fabião 2008), si bien no podemos descartar otros contenidos.

El resto de materiales de importación (cerámicas finas y lámparas) aparecen siempre en estado muy fragmentario y a menudo son hallazgos no estratificados.

Seguidamente efectuaremos un repaso de la evidencia conocida, así como una interpretación de la misma. En la exposición que seguirá, optamos por una periodización ordenada por siglos, y se tiene en cuenta el contexto histórico, a pesar de las posibles tendencias a forzar la interpretación en uno $\mathrm{u}$ otro sentido (como puede ser el caso de la crisis del siglo III), porque pensamos que no se pueden desligar los materiales de la actividad económica, y ésta tampoco de la realidad política y social de la época.

\section{SIGLO III}

El siglo III es un período de cambios muy problemático, en el que se produjeron algunas convulsiones importantes en el Este de Hispania, como la incursión de los francos en el año 264 (Járrega 2008), que ha generado algunos estratos de destrucción en Tarragona y en la villa de Els Munts (Altafulla), cerca de esta ciudad. Aunque los contextos de esta época son escasos, los materiales de relleno de una cisterna de Ampurias (Nolla y Aquilué 1984) documentan bastante bien el panorama cerámico de hacia el año 275 d.C. Se aprecia todavía una cantidad importante de sigillata africana A (formas Hayes 15 y 16), que convive con la sigillata 
africana C (forma Hayes 50); aparecen en abundancia las cerámicas comunes africanas (platos o tapaderas de borde ahumado, formas Hayes 23 B y Hayes 193). Están presentes aún las ánforas galas de la forma Dressel 30 (que dejaron de importarse poco después), y se encuentran también ánforas africanas y tripolitanas (Africana 1 A y B). Asimismo, se documenta todavía la presencia del ánfora bética de la forma Dressel 20 (que, como la Dressel 30 gala, desapareció poco más tarde), en coincidencia con la Dressel 23, en las fases iniciales de su producción.

Los estratos de destrucción de la villa romana de Vilauba, situada en el Nordeste de Cataluña, son más parcos en cuanto a la aportación de materiales cerámicos, aunque se aprecia la continuidad en el uso de la cerámica africana de cocina (Castanyer y Tremoleda 1999). En lo que atañe a los estratos de destrucción de la villa romana de Els Munts (Altafulla) y en el área urbana de Tarraco, no se han publicado en detalle, por lo que de momento no se pueden efectuar estudios ceramológicos.

Por ahora, no tenemos bastantes datos que nos permitan estudiar correctamente la continuidad o cambios que se debieron producir en el comercio. Podemos suponer que la incursión de los francos debió ser un elemento negativo, pero hay otros factores económicos que se nos escapan, al conocer bastante mal este período. La escasa presencia de sigillata africana $\mathrm{C}$ o ánforas africanas de esta época se tiene que sumar al hecho de que presentan unas tipologías que perduran a inicios del siglo IV en el primer caso, y que pese a llegar a la cuarta centuria en el caso de las ánforas, su tipología podría remontar también a finales del siglo II (forma Africana 1), con lo cual, en ausencia de contextos arqueológicos, es muy poco lo que se puede precisar sobre la materia.

\section{SIGLO IV}

La primera mitad del siglo IV, es decir, la época constantiniana, constituye una importante laguna, puesto que prácticamente no conocemos contextos arqueológicos de esta época. Tan sólo podemos destacar algunos de Tarragona (Aquilué 1992a, Remolà 2000), correspondientes probablemente a niveles de abandono de la parte baja de la ciudad (c/ Gasòmetre, 32, c/ Apodaca, 7, Pere Martell - Eivissa - Mallorca), con presencia de sigillata africana D (Hayes 58 B, 59, 61 A, 67 y $91 \mathrm{~A} / \mathrm{B}$ ), ánforas mauritanas (Keay 1), africanas (Africana 1 A, 2 A, 2 C y 2 D) sudhispánicas (Beltrán 68,
Keay 16, Almagro $51 \mathrm{C}$ - Keay 23) e itálicas (ánfora de Empoli). El contexto de Apodaca, 7, podría ser más antiguo, de la primera mitad del siglo, pues de las formas de sigillata africana D aparecen solamente la Hayes 58 B y la 61, mientras que la presencia de la forma Hayes 91, según se desprende de los listados publicados (Macías et al. 1997: 164-165) nos indica que el contexto de Gasòmetre, 32 es, cuando menos, de finales del siglo IV.

Las ánforas (mayoritariamente africanas) de las necrópolis suburbanas de Tarraco, especialmente la del Francolí estudiada por Keay (1984), así como las de la necrópolis de la c/ Pere Martell, el Parc de la Ciutat, c/ Prat de la Riba y c/ Ramón y Cajal (Remolà 2000), corresponden al siglo IV y la primera mitad del V, constatándose ánforas africanas (Africana 2 A y C, Keay 24, 25 en sus diversas variantes, 27 B, 35, 36, 39, 41 y 59) y sudhispánicas (Dressel 23, Almagro 51A/B-Keay 19 y Almagro 51C-Keay 23).

Corresponden también al siglo IV los contextos documentados en la factoría de salazón de la Ciutadella (Roses, Alt Empordà), el relleno del depósito de la villa de Can Sentromà (Tiana, Maresme), así como algunos contextos en las villas romanas de Darró (Vilanova i la Geltrú) y El Castell de Cubelles (ambos en la comarca de Garraf) y las villas de Les Albardes (El Vendrell, Baix Penedès) y Els Hospitals (Morell, Tarragonès). Esta escasez contrasta con el hecho de que corresponden a un período (el constantiniano y teodosiano) que se ha supuesto como de continuidad e incluso de revitalización de la economía en Hispania (Arce 1982).

Esta ausencia podría justificarse precisamente por la falta de obras, tanto públicas como privadas (cosa que podría reflejar esta continuidad, pero también ser un indicio de decadencia), con la posible excepción de Tarraco, que podría haber sido afectada por algún episodio bélico relacionado con la rebelión de Magnencio (Járrega 1990 b). Por lo tanto, los materiales del siglo IV se tienen que estudiar a menudo a partir de hallazgos descontextualizados.

En los estratos de construcción de la factoría de Roses se han documentado las formas Hayes 58, 59 B, 61 A y 67 de la sigillata africana D, así como un fragmento de base con decoración del estilo A-1 de Hayes. Estos materiales se asocian con monedas de Constantino I, Crispo, Constante, Constancio II (muy abundantes), Magnencio, Decencio, Juliano y, en menor cantidad, Valentiniano I y Valente (Nieto 1993, Nolla 1984: 445). Las piezas de estos dos últimos emperadores proporcionan una datación post quem para la construcción del citado edificio del 364 d.C.; la ausencia de monedas posteriores creemos que indica que dicha fecha no se 
aleja mucho de la real. Por lo tanto, se trata de un contexto del tercer cuarto del siglo IV, en el que el repertorio formal de la sigillata africana $D$ resulta el típico para esta época. Llama la atención la ausencia de la forma Hayes 91, que apareció probablemente algo más tarde, a finales del siglo IV o ya a inicios del V (Hayes 1980: 515, Reynolds 1995: 151, Bonifay 2004: 177-179, Quaresma 2008). Lamentablemente, no se han dado a conocer ánforas ni otros materiales significativos de estos estratos.

En la villa romana Can Sentromà (Tiana, comarca del Maresme), entre los materiales publicados por J. Guitart (1970) que corresponden al estrato de amortización de un gran almacén, se documentan las formas Hayes 58B, 59A y B, 61A, 67 de la sigillata africana D y una base estampada con decoración del estilo A-3 de Hayes. Aparece, por primera vez, sigillata gris estampada o "D.S.P."” (forma Rigoir 3) y un fragmento de la forma Dragendorff 37 de la sigillata hispánica tardía, con decoración del Primer Estilo de Mayet. Estos hallazgos son muy interesantes, dado que demuestran la importación de sigillata gris estampada y de sigillata hispánica tardía (procedente esta última probablemente de la Meseta o de la Rioja) en su versión más antigua, con decoración del Primer Estilo; asimismo, el fragmento del estilo A III de la decoración de la sigillata africana $\mathrm{D}$ corresponde al período más antiguo de dicho estilo, que se iniciaría así en el tercer cuarto del siglo IV.

Las monedas halladas en el citado estrato de relleno de Can Sentromà corresponden a Constantino I, Crispo, Constantino II, Constante, Constancio II y Juliano II, además de treinta y nueve ejemplares no identificables con precisión, pero que pertenecen con seguridad, según Guitart, a Constantino I o a sus hijos. Las emisiones dominantes son, añade Guitart, las del tipo Fel(icitas) Temp(orum) Reparatio, que se acuñaron hasta el año 361 d.C. La moneda más moderna es de Juliano, lo que nos proporciona un terminus post quem del año 363 d.C.; la ausencia de monedas posteriores a Juliano permite pensar que la datación del conjunto no puede ser muy posterior a dicha fecha, relativamente cercana a la de la fundación de la factoría de Roses. Como podemos ver, el repertorio formal de la sigillata africana D, bastante limitado, es idéntico al de la factoría de Roses, y sigue estando ausente la forma Hayes 91, indicio bastante claro de que su aparición es posterior.

En la villa romana de Darró (Vilanova i la Geltrú, Garraf) se han documentado algunos estratos correspondientes a remodelaciones de la villa, que han proporcionado el hallazgo de sigillata africana $\mathrm{C}$ (Hayes 50A) y D (formas Hayes 58 B, 59 B, 61 A), así como cerámica "lucente" (Lamboglia 1/3), cerámica africana de cocina (Ostia III, 108), ánforas africanas (Keay 24A y 27), y sudhispánicas (Keay 16, Almagro 51CKeay 23) que apuntan a una datación de mediados del siglo IV (López et al. 1997: 61-63 y 71-77, láms. IVII). También aquí la ausencia de la forma Hayes 91 es significativa. No existen noticias referentes a hallazgos monetarios que permitan calibrar la datación.

Muy cerca de la anterior, la villa romana de El Castell de Cubelles (también en la comarca del Garraf) sufrió una serie de remodelaciones datables (según sus excavadores) hacia el año 360; los estratos correspondientes aportan fragmentos de sigillata africana $\mathrm{C}$ (Hayes 50 A y 57) y D (Hayes 32/58, 59 A y B y 61 A), cerámica "lucente" (Lamboglia 1/3) y cerámica africana de cocina (Hayes 195, 196 y 199) (López et al. 1997: 63-64 y 78, lám. VIII). Por ello, aunque la datación propuesta por los autores quizás sea un tanto ajustada, es evidente que el contexto de los materiales corresponde a los tres primeros cuartos del siglo IV, siendo muy similar al de Darró.

También muy cerca de Darró y Cubelles conocemos la villa de Les Albardes (El Vendrell, Baix Penedès), donde se ha constatado un contexto (correspondiente a un terraplenamiento) datado a finales del siglo IV (Macías et al. 1997, 155 y 164-165), como lo indican las formas de sigillata africana D (Hayes 58 B, 59, 60, 61, 67 y especialmente 91), africana de cocina (Hayes 23 B) así como ánfora africana (Africana 1 y 2, Keay 25 C) y sudhispánica (Keay 16 y Almagro 51 C - Keay 23). La presencia de la forma Hayes 91 nos permite incluso sugerir una datación que pueda alcanzar los inicios del siglo $\mathrm{V}$.

La villa romana de Els Hospitals (Morell, Tarragonès) proporcionó un nivel constructivo asociado a un pavimento datado por sus excavadores en el segundo cuarto del siglo IV (Macías et al. 1997, 155-156 y 164165), con presencia de sigillata africana $C$ (Hayes 45 A, 48 y 50 A), D (Hayes 58 B y 61), "lucente", cerámica africana de cocina en abundancia (Hayes $23 \mathrm{~A}$ y B, 131, 196, 197, Ostia I, 270) y ánfora africana (Keay 7 y 35 A). El amplio repertorio de cerámica africana de cocina nos hace sospechar que hay abundante material residual, como hace pensar la presencia de sigillata africana A. Las (por otro lado escasas) formas de sigillata africana D apuntan a una cronologia de los tres primeros cuartos del siglo IV, aunque la aparente presencia del ánfora Keay 35 A no cuadra con esta cronología, y debería revisarse; tal vez corresponda en realidad a una variante de la forma Keay $35 \mathrm{~B}$.

En Tarragona, en la denominada "bóveda K" del circo romano, se ha documentado un contexto datable 
en la segunda mitad del siglo IV o inicios del V (Remolà 2000: 74), por la presencia de sigillata africana D (Hayes 58 B, 59, 61, 91 A/B y 67) y ánforas africanas (Keay 24, 25 B y 26 F) y béticas (Dressel 23, Almagro 51 A/B Keay 19 y Almagro 51 C - Keay 23), así como ánfora itálica de Empoli. De todos modos, la Hayes 91 permite pensar más bien en una cronología inicial del siglo V.

La falta de contextos impide estudiar series de materiales y hacer estadísticas, pero se constatan algunos parámetros, que exponemos seguidamente. En primer lugar, con respecto a la sigillata africana $\mathrm{C}$ tardía, se documenta la presencia esporádica pero constante, de la variante C3, y especialmente de la forma Hayes 73. Hay alguna representación (esporádica) de sigillata africana C con decoración aplicada figurada: Barcino, Tarraco, Dertosa, Roses, Pla de Palol, Camp de la Gruta, Pla de l'Horta, Caputxins, Torre Llauder, Sant Boi, Granollers y, quizás, Can Paxau (cf. Járrega 1993/2009).

A partir de la segunda mitad del siglo IV se generalizó la producción y comercialización de la sigillata africana D, cuyas formas cerámicas más importantes $(59$ A y B, 61 A, 60, 64 y 67 de la clasificación de Hayes), así como los primeros estilos decorativos de la producción estampada (estilos A-1 y A-2 de Hayes), que se documentan ampliamente en esta época. Se constata una presencia masiva, tanto en yacimientos urbanos como rurales, de esta producción, con la aparición de las formas mencionadas (especialmente de la Hayes 61 A), así como, hacia finales de siglo, las formas Hayes 91 A y B que, como hemos visto, se encuentran ausentes todavía en los contextos del tercer cuarto del siglo IV.

Se ha documentado una presencia discreta de la $\mathrm{si}$ gillata africana E (Járrega 1993/2009), que tanto se puede asociar al siglo IV avanzado como a inicios del siglo V. Presenta una distribución costera, con las formas Hayes 66, 68 y 92 que se han encontrado en Barcino, Barrugat (cerca de Tortosa, en las tierras del Ebro) y Vilardida (Alt Camp), por lo cual se trata sin duda de un producto subsidiario de la sigillata africana D (Járrega 1993/2009).

Se constata también la continuidad en la llegada de la cerámica africana de cocina. Su presencia es difícil de calcular porque, a pesar del hallazgo esporádico de formas claramente tardoantiguas, se produce una continuidad en la producción de formas anteriores (Hayes 182, 196 y 197) que dificulta diferenciar los productos del siglo IV y primera mitad del V de los de los siglos II y III, teniendo en cuenta los procesos de residualidad. Sin embargo, hay que observar una peor factura y especialmente un aumento del tamaño y un engrosamiento de los ejemplares tardíos, tema que todavía está por estudiar.
Con respecto a las importaciones galas, la sigillata "lucente" presenta, en el área catalana, una distribución básicamente costera, con algunas penetraciones hacia el interior, y presencia masiva de la forma Lamboglia 1/3. La denominada "D.S.P.", aunque es una producción típica del siglo $\mathrm{V}$, se inicia en el último cuarto del siglo IV. Su presencia en Can Sentromà podría corresponder a este momento.

La sigillata hispánica tardía, que se produjo durante los siglos IV y V, tiene una presencia relativamente abundante en el interior y en el litoral sur (Dertosa y área de Tarraco), mientras que se produce una virtual ausencia en el Norte del Maresme, hasta ser prácticamente ausente en la zona más septentrional (Gerona, Ampurias) (Járrega 1993-2009, con bibliografía anterior). Esta dicotomía indica probablemente un comercio fluvial por el Ebro o por tierra en dirección hacia Tarraco, que se rarifica en dirección Norte a partir del Maresme. En el primero de los supuestos, el puerto marítimo-fluvial de Dertosa (Tortosa) podría haber tenido un papel de intercambio excepcional, tanto para el comercio de estos materiales hacia la costa como los de productos mediterráneos hacia el interior.

Una posible razón de su rarificación al Norte del Maresme podría ser la fuerte competencia que presentan los productos gálicos ("lucente" y "D.S.P."). Podemos preguntarnos si se trata de una comercialización por vía marítima (como parece) o terrestre, o una combinación de ambas (la presencia en el Vallès podría haber sido fruto de una redistribución desde Barcino). En contraste con la zona costera, en el interior la sigillata hispánica tardía es más importante, superando numéricamente a los productos africanos.

En cuanto a las lucernas, sólo conocemos producciones africanas, sin haberse identificado imitaciones. La forma que corresponde a estos momentos es la Hayes IAtlante II, que tenemos presente (siempre en poca cantidad) en los principales yacimientos urbanos (Barcino, Tarraco) y en algunos rurales, pero su continuidad a lo largo del siglo $\mathrm{V}$ impide concretar la presencia de estas formas durante el siglo IV, al faltar contextos de la época. Parece, sin embargo, tratarse de una importación esporádica, en comparación con otros productos africanos.

Con respecto a las ánforas, se constata un predominio absoluto, durante el siglo IV, de las producciones africanas (Africana 1 y 2, y Africana 3 - Keay 25), con alguna distribución de ánforas mauritanas (Keay I). El ánfora Africana 3 - Keay 25, es la más significativa del siglo IV, con una importante representación en la necrópolis del Francolí en Tarragona. En un conjunto documentado en la c/ Apodaca núm. 7 de Tarragona (Macías et al. 1997, 165; Remolà 2000: 87-88), fechado en la 
primera mitad siglo IV, las ánforas africanas (Africana 1 y 2) son el $74 \%$ del total, mientras que $19 \%$ son sudhispánicas (Keay 16, Almagro 51 C - Keay 23 y Beltrán 68) y alguna empolitana (correspondiente al 7\% restante), que se encuentra también en otros contextos de la ciudad. En el contexto rural de Les Albardes (Macías et al. 1997:165), en el territorio de Tarraco, que se fecha en la segunda mitad del siglo, conviven la Africana 1 y 2 con la Africana 3 - Keay 25, concretamente la $25 \mathrm{C}$, con una marca NCT. Si bien no conocemos su contenido (que pudo haber sido múltiple), la preponderancia de las ánforas africanas es evidente.

Junto con las producciones africanas, y en muy escasas cantidades, podemos documentar las ánforas sudhispánicas, tanto béticas (representadas por la forma Dressel 23) como lusitanas (formas Almagro $51 \mathrm{~A} / \mathrm{B}$ Keay 19 y Almagro $51 \mathrm{C}$ - Keay 23, que podría también haberse producido en parte en la Baetica), que sirvieron claramente para contener aceite en el primer caso y para salazones u otros productos en el segundo. Estas ánforas se documentan a lo largo de la costa catalana (Berni 1998, Járrega 2000a) siempre en una cantidad más pequeña que las ánforas africanas. Finalmente, a finales del siglo IV comenzaron a llegar las primeras ánforas orientales, cuya presencia sería más importante en el siglo siguiente, por lo que no son significativas en los contextos catalanes del siglo IV.

En resumidas cuentas, podemos afirmar que, a pesar de la concurrencia de otros productos, unos procedentes de la Gallia (sigillata "lucente" y "D.S.P.") y otros del interior y del Sur de Hispania (sigillata hispánica tardía, ánforas sudhispánicas), se produjo un predominio absoluto de la producción africana, que tiene una distribución básicamente costera pero que presenta una importante capilaridad hacia el interior, llegando incluso a las villas ilerdenses (el Romeral de Albesa), si bien estas producciones se rarifican rápidamente más al interior, aunque están presentes en ciudades importantes, como Ilerda (Lleida) y Caesaraugusta (Zaragoza).

Es interesante subrayar que no se detecta ninguna ruptura comercial entre los núcleos urbanos y las zonas rurales (villae), pues aunque las ciudades presentan una cantidad mucho mayor de materiales, la presencia de producciones diversas y la proporción entre ellas son similares en la ciudad que en el campo.

\section{SIGLO V}

Contamos con contextos del siglo V especialmente en la ciudad de Tarragona. El más famoso es el de la c/ Vila-roma (Ted'a 1989), que corresponde al parecer a un vertedero urbano, con presencia abundante de $s i$ gillata africana D (formas Hayes 80 A y B, 81 A, 91 A y $\mathrm{B}$, además de otras más antiguas, como las Hayes 59 y la 63), sigillata "lucente" (Lamboglia 1/3 y 2/37), "D.S.P.” gris y anaranjada (Rigoir 1, 3, 6, 9, 18 y 26), sigillata hispánica tardía (Dragendorff 37 tardía), cerámica pintada tardorromana, así como ánforas africanas (Africana 1 y 2, Keay 24, 25 en diversas variantes, 26 F, 27 B, 35 A y B), orientales (Late Roman Amphora 1, 2, 3, 4 y 5) y sudhispánicas (Dressel 23; Keay 16, Almagro 51 A-B - Keay 19 y Almagro $51 \mathrm{C}$ - Keay 23). Este contexto fue inicialmente datado, con excesiva precisión, hacia los años 430-440. Es cierto que la gran mayoría de los materiales pueden fecharse sin problemas dentro de la primera mitad del siglo V, pero existen algunos fragmentos de sigillata africana D (Hayes $87 \mathrm{~A}$ y B, 94 y 99) y ánforas africanas (Keay 61 y 62), lo que ha permitido datar la fecha final del vertedero en la segunda mitad del siglo V (Reynolds 1995: 281, Járrega 2000a: 468), o bien se han considerado directamente como intrusiones (Remolà 2000, 48). Hay que considerar que las formas Keay 61 y 62 son mucho más tardías, sean intrusiones o correspondan a un uso limitado del vertedero en los siglos VI y VII. De todos modos, la presencia de estos materiales limita, desgraciadamente, el valor del contexto de la c/ Vila-roma como conjunto cerrado, e invita a considerar la datación de sus materiales con precaución.

Además del de la c/ Vila-roma, la antigua Tarraco ha proporcionado otros contextos de esta época (Aquilué 1992a, Remolà 2000), quizás menos conocidos pero tanto o más significativos que aquél. Se han documentado especialmente en el casco antiguo o parte alta de la ciudad (claustro de la Catedral, el antiguo Hospital de Santa Tecla, c/ Mercería 11, Torre de la Audiencia 1 A y 1 B, c/ Santes Creus, 5-9, plaza de Rovellat y plaza dels Àngels). Estos contextos se pueden datar en la primera mitad o mediados del siglo $\mathrm{V}$, por la presencia de las formas Hayes 61 B, 80 A, 81, 91 A/B de la sigillata africana $\mathrm{D}$ (además de otras más antiguas, como la Hayes 59, 61 A y 67) cerámica "lucente" (Lamboglia 1/3), "D.S.P." gris y anaranjada (Rigoir 2, 3, 4, 6, 8, 9, 15, 18, 24, 26, 29, 35 A y B, 36, 41), Late Roman C (o Phocaean Red slip ware; forma Hayes 3), sigillata hispánica tardía (Draggendorf 37 tardía), así como ánforas africanas (formas Africana 1 y 2, Keay 24, 25, 26, 27, 35 A y B, 41), sudhispánicas (Dressel 23, Keay 16 A, Almagro 51 A/B - Keay 19) y orientales (Late Roman Amphora 1, 2, 3 y 4), así como escasos ejemplares de origen itálico (ánfora de Empoli y Keay 52) que 
apuntan a esta cronología (Rüger 1968 para el claustro de la catedral, para el resto Aquilué 1992, Remolà 2000). En el caso del claustro de la catedral se halló una moneda de Honorio, lo que nos da una clara datación post quem del primer cuarto del siglo V. Sin embargo, en algunos casos (antiguo Hospital de Santa Tecla, Torre de la Audiencia 1 A y 1 B, plaza dels Àngels) se han hallado formas más recientes (Hayes 79, 80 B/99, 86, 87 A y B, 12 y 102) que corresponden ya a finales del siglo $\mathrm{V}$ o inicios del VI, lo que representa un problema para la datación real de estos contextos, similar al que hemos visto en relación con el contexto la c/ Vila-roma.

Aunque la mayoría de los contextos de esta época se han localizado en Tarraco, contamos con algunos documentados en otros yacimientos. Concretamente, en Barcino, los escasos materiales hallados en el pavimento de un aula episcopal anexa a la basílica han proporcionado fragmentos de las formas Hayes 59, 61 A y 91 (probablemente A o B), decoración estampada del estilo A de Hayes y "D.S.P.” gris de la forma Rigoir 6 o 18, además de cerámica común grosera; todo ello proporciona una datación comprendida entre los años 380-420 d.C., lo que concuerda con los hallazgos monetarios (Járrega 2005b: 231-234 y 243, lámina 2); probablemente la datación más adecuada sea dentro de la primera mitad del siglo $\mathrm{V}$.

En la plaza Mayor de Sant Martí d'Empúries se excavó un contexto correspondiente a un vertedero (Aquilué 1997). Entre los materiales del mismo se documentó sigillata africana D (Hayes 58 B, 61 A y B, 63, 67,80 A, 81 A y 91 A y A/B), lucerna africana (forma Hayes I - Atlante VIII), cerámica "lucente" (Lamboglia 1/3, 9 B y 14), “D.S.P.” gris (Rigoir 1 y 18), así como posibles imitaciones de ésta. En cuanto a las ánforas, destacan especialmente las africanas (formas Keay $25 \mathrm{~B}$ y P, 26 F, 27 B y 35 B), apareciendo también las orientales (Late Roman Amphora 1, 3 y 4, así como posible Late Roman Amphora 2) y sudhispánicas (Keay 16, Almagro 51 A/B - Keay 19 y Keay 78), y un ejemplar de ánfora itálica Keay 52. Por ello, Aquilué (1997: 86) fecha acertadamente este contexto en la primera mitad del siglo V, con una tendencia hacia el primer cuarto, si bien la presencia de la forma Keay $35 \mathrm{~B}$ nos permite apuntar más bien hacia el segundo cuarto del mismo.

En Iluro (Mataró) abundan los materiales del siglo IV y primera mitad del V, principalmente la sigillata africana D y en especial la forma Hayes 61 (Cela y Revilla 2004: 351), pero se trata siempre de materiales residuales hallados en contextos más recientes.

Por otro lado, en la villa romana de Darró (Vilanova i la Geltrú, Garraf) el estrato de relleno de un pozo proporcionó un contexto de la primera mitad del siglo $\mathrm{V}$ (datable hacia el segundo cuarto del siglo, según sus excavadores), con presencia de sigillata africana D (Hayes 61 B, 67, 76, 81, 91 A o B), "D.S.P.” gris y anaranjada (Rigoir 1, 6, 15 y 18) y cerámica africana de cocina (Hayes 196) (López et al. 1997: 64-65 y 79-80, láms. 9 y 10). Aparentemente también están presentes las ánforas orientales, a partir de un posible fragmento de Late Roman Amphora 1 (López et al. 1997: 80, lám. X.11; clasificada como cerámica común romana).

Ésta es una época de convulsiones políticas, empezando por la primera penetración bárbara en Hispania el año 410 (que no tenemos indicios para pensar que afectara a Cataluña), la llegada de los visigodos como aliados de Roma (presencia de Ataúlfo en Barcino en el año 415) y finalmente la conquista manu militari de las maritimae civitates por parte del rey visigodo Eurico (hacia los años 470-475). A todo ello hay que añadir la conquista de Cartago por parte de los vándalos en el año 439 ¿Cómo afectaron, y en qué medida, estos hechos políticos y militares en las relaciones comerciales en la costa hispánica? Muy a menudo se ha tendido, tradicionalmente, a forzar los datos arqueológicos a partir de una determinada interpretación de las informaciones proporcionadas por las fuentes escritas, pero no tenemos que olvidar (aunque parezca una obviedad) que los hallazgos arqueológicos son el resultado de un determinado proceso histórico, y que un período de inestabilidades tiene que tener, de un modo u otro, un reflejo en los datos arqueológicos.

La tardía fecha de la conquista de Eurico indica que el área catalana fue una de las últimas posesiones del Imperio romano de Occidente, como lo permite constatar una inscripción de Tarraco dedicada a León y Antemio, una de las últimas del Imperio romano (CIL 02, 04109=RIT 0100). Ello probablemente favoreció la continuidad en el comercio, pero como veremos, ésta perduró más allá del fin del Imperio romano de Occidente.

Sin embargo, la conquista vándala de Cartago en el año 439 comporta un problema de interpretación, porque debió afectar tanto a los centros productores como a los consumidores. Es difícil de valorar su importancia, ya que no existe unanimidad entre los diferentes investigadores que se han ocupado del tema. Se ha sugerido que la invasión vándala causó una crisis en la producción de las sigillatae y ánforas norteafricanas, que provocó una recesión en la comercialización de las mismas (Hayes 1972: 423), la cual fue aprovechada por los comerciantes orientales para introducir sus productos en el Mediterráneo occidental. Incluso se ha llegado a pensar que esta "crisis" o recesión se inició en época algo 
anterior a la conquista vándala, y por lo tanto, sin ninguna relación de causa-efecto con ella (Fulford y Peacock 1984: 113). Este esquema, de por sí discutible por no probado, ha sido contestado por algunos autores (Tortorella 1987: 301), y las evidencias que conocemos nos obligan, si no a rechazarlo, sí a matizarlo grandemente.

Bastante elocuente es el caso del contexto de la c/ Vila-roma en Tarragona (situado en el área del antiguo foro provincial), que es un poco más moderno de lo que se había dicho, ya que se había fechado (con una precisión excesiva) en los años 430-440 (Ted'a 1989), pero que ahora se puede llevar al tercer cuarto del siglo $\mathrm{V}$ (Reynolds 1995: 281, Járrega 2000a: 468), mediante el hallazgo en este contexto de fragmentos de sigillata africana D de las formas Hayes 87 A y B, 91 C y 99. Es cierto que, a diferencia de lo que se había querido hacer en el caso del ejemplo tarraconense que acabamos de mencionar, no es fácil fechar los contextos de la primera mitad o medios del siglo $\mathrm{V}$, con lo cual resulta difícil atribuirlos a un momento anterior o posterior a la conquista vándala de Cartago.

En cualquier caso, parece claro que no hubo una ruptura del comercio, aunque los datos arqueológicos no pueden iluminar la situación en los momentos inmediatos a la conquista de Cartago. Así, es tentador relacionar las destrucciones urbanas documentadas en Valentia durante la primera mitad del siglo $\mathrm{V}$, como lo indica la presencia en un estrato de destrucción (excavado en la zona del foro de la ciudad) de la forma Hayes $91 \mathrm{~B}$ de la $s i$ gillata africana D, así como lucernas Hayes I-Atlante VIII y ánforas de las formas Africana 2 (clasificada erróneamente como Keay 35), Dressel 23 y Keay 19 y 52 (Álvarez et al. 2005: 257; 258-259, figs. 7-8), con una incursión pirática de los vándalos, los cuales se habían hecho con el control de las islas Baleares. Ciertamente, este panorama parece dificultar la visión de un comercio normal entre Africa e Hispania en aquellos momentos.

Por contra, sabemos que durante la segunda mitad del siglo $\mathrm{V}$, el reino vándalo se asentó y se organizó, lo cual favoreció una regularización del comercio de los productos africanos, que serían distribuidos bajo el dominio de dicho reino. Los cambios tipológicos que se observan tanto en las sigillatae como en las ánforas africanas podrían guardar relación con esta reconversión del comercio africano. A finales siglo V ("deuxième époque vandale", como la denomina Bonifay) la comercialización exterior de la producción africana recuperó el nivel anterior, del siglo IV e inicios del V (Bonifay 2004: 472). Habrá que valorar si eso se puede afirmar también para las áreas objeto de exportación, como la que aquí nos ocupa.
La desaparición de las obligaciones de la annona implicó que todos los productos que estaban destinados a la misma aumentasen ahora los stocks de producción, lo que obligaría al reino vándalo a liberar estos stocks. Esta es la causa, según Keay (1984 B/II: 426-427) de la gran cantidad de ánforas africanas de la segunda mitad del siglo V e inicios del VI que se han hallado en la zona costera catalana; según el citado autor, podría considerarse incluso este territorio como una suerte de mercado preferente, alentado por las buenas relaciones existentes entre los reinos vándalo y visigodo. Todo ello cuadra perfectamente con la situación de estabilidad e institucionalización que el reino vándalo vivió a finales del siglo $\mathrm{V}$, en la que destacan algunos monarcas como Guntamundo y Trasamundo.

La similitud de los contextos arqueológicos de los siglos VI y VII en el Mediterráneo occidental se debe probablemente a la libertad de comercio proporcionada por los distintos reinos bárbaros de esta zona, hasta el punto de que se ha llegado a hablar de una koiné comercial existente en esta parte del Mediterráneo (Murialdo 2001c: 306), lo que probablemente se vio favorecido por la desaparición de la annona imperial.

A finales del siglo $\mathrm{V}$ o muy a inicios del VI podrían corresponder algunos de los contextos de Tarragona anteriormente mencionados (Aquilué 1992a) así como el excavado en el yacimiento rural de Can Modolell (Cabrera de Mar, Maresme, Barcelona) (Clariana y Járrega 1990, Járrega y Clariana 1996). En ambos casos están presentes las formas de sigillata africana $\mathrm{D}$ del último cuarto del siglo V e inicios del VI: Hayes 87 A, B y C, Hayes 88, 99, 103, 104 A y la taza Hayes 12.

También son de esta época los estratos de aterrazamiento del denominado cardo maximus de Iluro (Mataró), con presencia de formas de sigillata africana D de este período (Hayes 80, 81, 87 A y B, 91 A, B y C, 93 B, 94 B, 99 A y B, 104 A y 12/110), así como, en menor número, "D.S.P.", ánforas africanas (especialmente Keay 62) y algunas ánforas orientales (Late Roman Amphora 1 y 2, así como un único caso de ánfora egipcia Late Roman Amphora 7); sin embargo, estos estratos presentan abundante material residual (Cela y Revilla 2004: 351-355).

Aunque todo indica que proceden de un contexto más tardío (con lo que se trataría de material residual) es destacable la relativa abundancia de la forma Hayes 87 A de la sigillata africana D en las excavaciones de la plaza de Font y Cussó de Badalona (Comas y Padrós 1997: 126, fig. 2), lo que invita a pensar que a Baetulo llegaron también sin problemas materiales africanos a finales del siglo $\mathrm{V}$ o inicios del VI. 
Estos contextos invitan a pensar que, aun en el caso de que la invasión vándala en el segundo cuarto del siglo V hubiese afectado la producción y el comercio de la cerámica africana, el posterior reforzamiento del reino vándalo africano comportó una fase de mantenimiento y extensión del comercio de estas cerámicas, que se debe relacionar seguramente con los cambios tipológicos que experimentaron en este período tanto la sigillata africana como las ánforas.

La presencia en el Mediterráneo occidental de cerámicas de la zona oriental del mismo no creemos que deba explicarse necesariamente por una crisis de la producción africana, sino que pudo (y, de hecho, creemos que debió) ser provocada por otras causas, pues se documentan en el Occidente mediterráneo ya durante la segunda mitad entrada del siglo IV, detectándose en contextos de época teodosiana. Ello supone una introducción de los productos orientales en la zona de potencial competencia de estos productos, aunque ello no tiene, a nuestro entender, por qué deberse a una recesión de la producción africana, sino más bien (y por qué no) a una mayor presión en la oferta por parte de los comerciantes orientales.

Con respecto a las cerámicas finas, se detecta una continuidad (en cantidades discretas) de la sigillata africana $\mathrm{C}$ tardía, concretamente de la $\mathrm{C} 4$, que aparece esporádicamente en los núcleos urbanos (Barcino y Tarraco), pero también en los centros rurales próximos a los mismos (Can Modolell, en Cabrera de Mar; en este caso, en un contexto del último cuarto del siglo V). La presencia de estas cerámicas podría ser un reflejo de la reactivación del comercio una vez asentado el reino vándalo. Destaca la forma Hayes 84 , así como (y especialmente) la Fulford 27 (producida, al menos en parte, en el taller de Beni Khiar - Sidi Zahruni), relativamente abundante dentro del total de la producción (Fulford y Peacock 1984: 57, Reynolds 1987: 18, Járrega 19932009: 1336). Reynolds (1987: 18) remarca el hecho de que en la zona de Alicante es más abundante la forma Fulford 27 que la Hayes 84 típica, lo cual coincide con los hallazgos efectuados en Cataluña, donde la forma Hayes 84 aparece sólo en cinco yacimientos (Járrega 1993-2009: 1336), frente a los seis o siete donde está presente la Fulford 27. (Fig. 2)

Como sucedía en el siglo IV, la sigillata africana $\mathrm{D}$ es la cerámica fina mejor representada. Se constata una presencia, en la primera mitad del siglo V, de las formas Hayes $61 \mathrm{~B}$ (incluso de las variantes tardías que identifica Bonifay, y que algunos han confundido con la Hayes 104 A), la Hayes 91 A y B y la Hayes 76. Estas cerámicas reflejan la continuidad de los patrones de comercio del siglo anterior, antes de la conquista vándala de Cartago y quizás durante los primeros años de la misma (contexto de la c/ Vila-roma, en Tarragona).

La forma Hayes $61 \mathrm{~B}$ no aparece en los estratos antes mencionados de Roses y Can Sentromà, lo cual confirma que se originó a finales del siglo IV o, más probablemente, a inicios del V, como ya había propuesto Hayes (1972: 107) y confirman los estudios posteriores (Bonifay 2004: 171). Así, aparece en el vertedero de la c/ Vila-roma, en Tarragona, donde a pesar de la revisión a la baja de la cronología, la mayor parte de los materiales del conjunto apuntan hacia la primera mitad - mediados del siglo V.

Se documenta (especialmente en el contexto de la c/ Vila-roma, en Tarragona) la aparición del nuevo repertorio de formas de la sigillata africana D propio de este siglo (Hayes 80 A y B, Hayes 87); en el caso de la Hayes 87 , especialmente en su variante A (pero también en las B y C) existe una distribución bastante importante (Járrega 1991: 40-43, Járrega 1993-2009: 1379), correspondiente a la segunda mitad del siglo V, que podemos asociar a la reactivación del comercio africano bajo los auspicios del reino vándalo.

El contexto de Vila-roma permite plantear la continuidad en la llegada de cerámicas de cocina africanas hasta al menos mediados del siglo V (formas Ostia III, fig. 170; Ostia I, fig. 261; Ostia III, fig. 267; Villa-roma 540) pero los problemas tipológicos mencionados más arriba impiden estudiarlas en otros contextos y diferenciarlas de los elementos residuales, así como fijar el momento final de esta producción, que no parece perdurar más allá del siglo V (a diferencia de las sigillatae y las ánforas). Por lo tanto, tenemos aquí un problema tipológico, que es necesario relacionar con contextos bien fechados, y valorar la posible residualidad de las cerámicas africanas de cocina halladas en los mismos.

Tenga o no una relación directa con una posible mayor apertura de los mercados del Mediterráneo occidental en los productos orientales debido a la presencia vándala en África, lo cierto es que se constata la llegada (poco abundante, pero sostenida) en Cataluña de la Late Roman C (o Phocaean Red Slip ware), representada especialmente por la forma Hayes 3; ya Nieto (1984) apreció su implantación. Su distribución se limita al área costera, apareciendo especialmente en zonas urbanas (Barcino, Tarraco, Sant Martí d'Empúries, Roses), pero también en ámbitos rurales, aunque próximos a los núcleos urbanos, como en el caso del Camp de la Gruta (Torroella de Montgrí), Vilauba (Camós) y Centcelles (Constantí) (Járrega 1993-2009). 


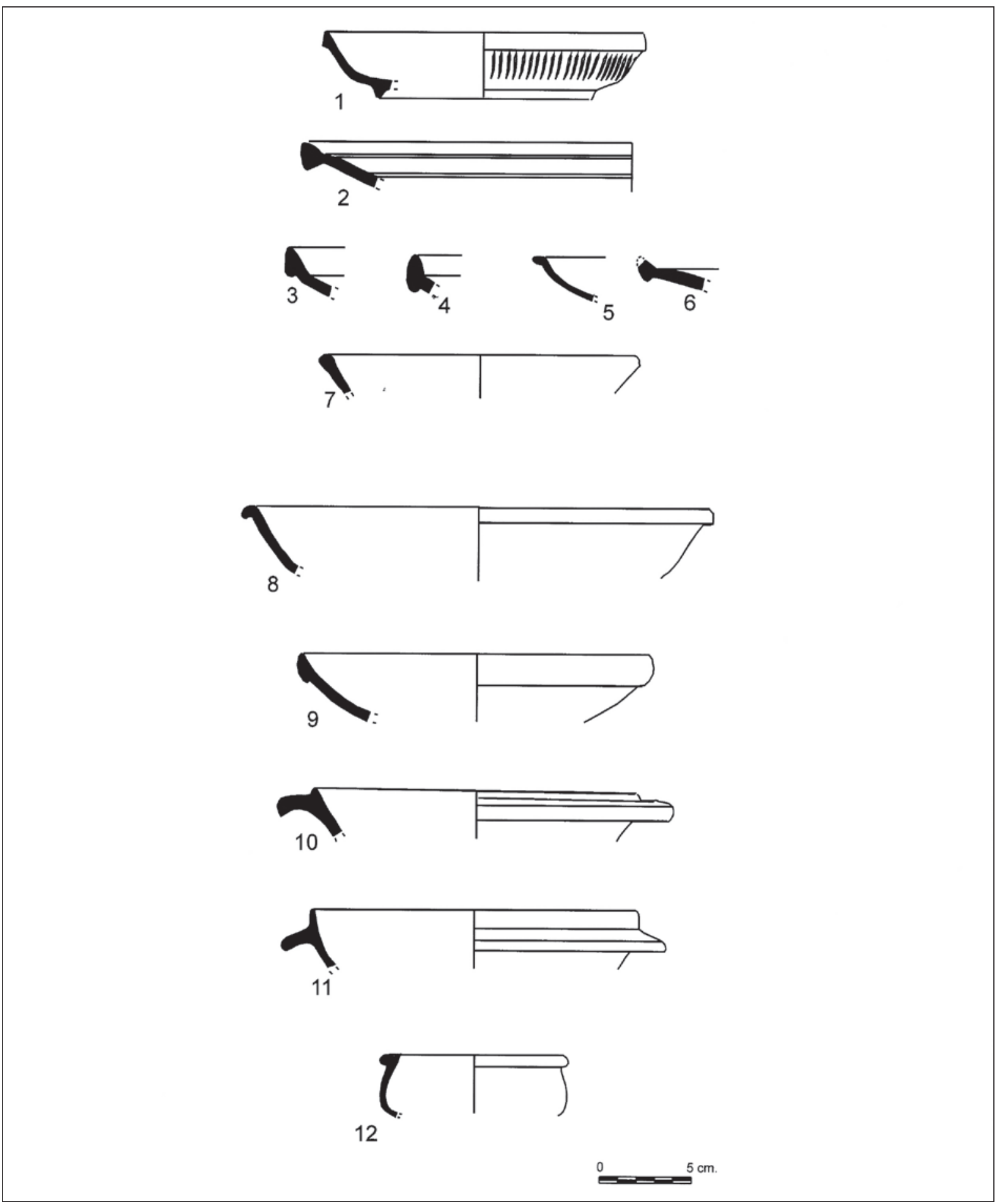

Figura 2. Cerámicas africanas del contexto tardoantiguo de Can Modolell (Cabrera de Mar), finales del siglo V o inicios del VI (dibujos: J.-F. Clariana): 1. Sigillata africana C tardía, forma Fulford 27. 2. Sigillata africana D, forma Hayes 76. 3. Sigillata africana D, forma Hayes 87 A. 4. Sigillata africana D, forma Hayes 104 A. 5. Sigillata africana D, forma Hayes 93 B. 6. Sigillata africana D, forma Hayes 88. 7. Sigillata africana D, forma Hayes 80 A. 8. Sigillata africana D, forma Hayes 93 B. 9. Sigillata africana D, forma Hayes 99 B o C. 10. Sigillata africana D, forma Hayes 91 B. 11. Sigillata africana D, forma Hayes 91 C. 12. Sigillata africana D, forma Hayes 12. 
Otras producciones de origen mediterráneo son menos abundantes, como la sigillata chipriota (Late Roman D), que aparece en otros puntos de la costa hispánica, como Cartagena (Méndez y Ramallo 1985: 264). Se documenta, en poca cantidad, en las áreas urbanas (Tortosa), pero también rurales (Can Modolell, en Cabrera de Mar, comarca del Maresme; Molins Nous, en Riudoms, comarca del Baix Camp, cerca de Tarragona). Se documentan las formas Hayes 2 y 9 (en Molins Nous). Probablemente llegó como un producto subsidiario de las ánforas orientales.

Más exótica todavía resulta la presencia de la sigillata egipcia, de la cual tenemos un posible ejemplar de cerámica egipcia B encontrado en Iluro, actual Mataró (Járrega y Claro 1994 b). También debemos poner de relieve el hallazgo de un ejemplar de posible sigillata egipcia $\mathrm{C}$ en el yacimiento de Les Vinyes (Vilarodona, Alt Camp) (Járrega 1993/2009). Aunque se trata de identificaciones dudosas, de todos modos, la sigillata egipcia se documenta con seguridad en Cartagena (tipos egipcia A y C; $c f$. Amante y Pérez 1995). La explicación de su presencia es la misma que la de la sigillata chipriota, es decir, que posiblemente llegaron acompañando las ánforas del Mediterráneo oriental, pero no podemos hablar de una comercialización de estos materiales.

Con respecto a las importaciones gálicas, la sigillata "lucente" siguió llegando hasta medios del siglo V; los ejemplares de la c/ Vila-roma, en Tarragona (Ted'a 1989: 176-179), deben corresponder a esta cronología, siempre que no sean residuales, lo cual no podemos descartar completamente.

La denominada "D.S.P." tiene una importante difusión en la primera mitad del siglo V, tanto en las áreas urbanas como las rurales (Járrega 1993-2009), lo cual indica una amplia presencia que permite plantear una competencia con la sigillata africana $\mathrm{D}$. Su distribución se hizo sin duda por vía marítima (desde los puertos de Marsella y Narbona) pero no podemos descartar la difusión terrestre. El período de máxima expansión parece que se produjo durante la primera mitad del siglo $\mathrm{V}$, pero llega claramente a mediados - segunda mitad (como indica el contexto tarraconense de la c/ Vila-roma, aunque parece que hay bastantes materiales de la primera mitad del siglo) e incluso finales de esta centuria, como se desprende claramente de los hallazgos de Can Modolell (Járrega y Clariana 1996), que no parecen residuales, ya que se trata de platos enteros, y no encontramos materiales del siglo IV en este yacimiento.

No es fácil determinar la atribución al grupo provenzal o al languedociano de las "D.S.P." encontradas en Cataluña, pero en todo caso podemos suponer una distribución a partir de los puertos de Marsella o de Narbona que continúa, de alguna manera, la tradición de la sigillata gálica altoimperial o el vino galo.

Se constata una preponderancia de las "D.S.P." de cocción reductora, aunque hay una presencia importante de la producción oxidante. Bacaria (1991) ha supuesto la existencia de imitaciones hechas en el área catalana, pero no se han detectado los talleres, y a falta de estudios arqueométricos creemos que mayoritariamente se trata de importaciones gálicas de menor calidad que la producción "standard".

Una cuestión que no se ha planteado es si, además de la competencia con las cerámicas africanas (evidente, en el caso de platos como la Rigoir 1, que imitan la producción de vajilla de plata pero también los platos de africana D de la forma Hayes 59), algunos productos como la cerámica "lucente", la "D.S.P." o la sigillata hispánica tardía representan una cierta complementariedad con la misma, al ofrecer formas cerradas (vasos para beber, boles o cuencos) que escasean en la producción africana, más especializada en platos y cuencos.

De la continuidad de la sigillata hispánica tardía durante la primera mitad del siglo V son un claro testimonio los hallazgos de un vertedero (lo que Serra Vilaró denominó "Choza del sepulturero"), en la necrópolis del Francolí de Tarragona (Serra 1929: 70, figs. 44-47). $\mathrm{Su}$ presencia en el contexto de la c/ Vila-roma, en la misma ciudad (Ted'a 1989: 226-229), podría indicar una continuidad hasta mediados o el tercer cuarto del siglo V, a menos que se trate de productos residuales. En todo caso, se constata una rarificación y desaparición de esta producción a partir de la segunda mitad del siglo V (tanto en los centros productores como en los receptores) por razones que desconocemos. Así, ya está ausente en los contextos de la segunda mitad del siglo, como el de Can Modolell antes mencionado.

Un grupo cerámico muy interesante y hasta ahora muy poco estudiado es la cerámica pintada tardorromana, cuyo período de producción parece situarse en el siglo $\mathrm{V}$, sin que podamos descartar su presencia ya en el siglo IV. Es una producción muy mal conocida, habiéndose efectuado sólo un estudio monográfico sobre la misma (Abascal 1986). Su textura y decoración, así como el engobe, hacen pensar en una única área de producción, pero es desconocida; podría proceder de la Meseta (donde es más abundante), y relacionarse su distribución con la de la sigillata hispánica tardía. Se ha documentado (en poca cantidad) en diversos yacimientos, como Torre Llauder (Mataró, Maresme), Barcelona (plaza del Rey y Tinell), La Torrassa 
(Hospitalet de Llobregat), La Presó (Granollers), Torrent de l'Apotecari (La Garriga), Cova de la Guanta (Sentmenat), Can Bosch de Basea (Terrassa), Cal Quec I (Castelfollit de Riubregós), en la provincia de Barcelona; Vilardida (Montferri), Mas del Catxorro (Benifallet) y Barrugat (Bítem), en la provincia de Tarragona, y quizás Can Brunet (Òdena) (Járrega 1993/2009: 14641465), así com La Ferrera (Sant Vicenç de Montalt, provincia de Barcelona) (Arqueociència 1995: 139, fig. 5, 39-40) y Casa Blanca (Tortosa, provincia de Tarragona; Revilla 2003: 79, fig. 29, 8-9; 110, fig. 44, 10-11). También podemos citar un bello ejemplar entero, recientmente publicado, hallado en la villa romana de Els Tolegassos (Viladamat, provincia de Gerona), que es una botella con una decoración pintada que consiste en una representación de peces, procedente de un contexto datado hacia el tercer cuarto del siglo IV (Casas y Soler 2003: 233-235 y 237), y más al sur, la villa de Els Munts (Altafulla), así como la necrópolis del Francolí y el contexto de la c/ Vila-roma, en Tarragona (Serra 1929: 70, figs. 44-47, Abascal 1986: fig. 155, 808-812; Ted'a 1989: 226-229, Járrega 1993/2009: 1194). Sin embargo, debemos tener en cuenta el hallazgo de otras cerámicas pintadas en contextos mediterráneos, como la cerámica pintada del "tipo Crecchio" (Staffa 1998: 459, fig. 12c), y unas tinajas, también pintadas, halladas en Paleapoli, en el sur de Italia (Raimondo 1998: 536, fig. 3.1). Por lo tanto, la atribución de las cerámicas pintadas encontradas en la costa a talleres ubicados en el interior de Hispania creemos que se tendría que revisar.

El siglo $\mathrm{V}$ es también un momento de cambio tipológico en las lámparas africanas, ya que se empezó a producir la lucerna del tipo Hayes II - Atlante X, que se distribuyó especialmente a partir del segundo cuarto del siglo V (Anselmino 1986, Pavolini 1986). No obstante, parece que la Hayes I - Atlante X continuó siendo mayoritaria hasta medios o el tercero cuarto del siglo V, ya que es la única forma documentada en el contexto de Vila-roma (Ted'a 1989: 182-189), donde todavía no aparecen las Hayes II - Atlante X. Éstas últimas sí que se encuentran en el contexto de Can Modolell (Járrega y Clariana 1996: 139-140, fig. 10) que fechamos hacia el último cuarto del siglo V. Con respecto a los ejemplares sin contexto arqueológico, podemos pues suponer que las lámparas de la forma Hayes I corresponden al siglo IV y los tres primeros cuartos del siglo V, mientras que las de la Hayes II pueden probablemente pertenecer al último cuarto de este siglo o a la centuria siguiente, comercializándose hasta el siglo VII. (Fig. 3)

Las ánforas presentan el panorama más diversificado de la centuria, ya que, a pesar de la preponderancia de las producciones africanas, existe una importante representación de las producciones orientales. Debemos interrogarnos acerca de cuáles fueron los productos que se comercializaron en estos contenedores: aceite africano, así como otros productos como salazones o frutas o incluso vino de esta procedencia; aceite bético; productos béticos o lusitanos indeterminados, probablemente salazones; aceite o vino de Siria y Turquía; vino de Gaza, etc.

Continuaron teniendo una gran importancia los contenedores africanos, pero ahora en competencia más directa con producciones orientales y sud-hispánicas. Aunque Keay (1984) había supuesto una abrumadora mayoría de la producción africana, esto ahora se puede matizar, a partir del contexto de la c/ Vila-roma, en Tarragona (Ted'a 1989: 249-320), en consonancia con lo que aportan otros contextos mediterráneos, como en Roma, los de la Magna Mater y la Schola Praeconum, en el Palatino (Whitehouse et al. 1982, Carignani et al. 1986), en los cuales los porcentajes aparecen más repartidos.

En este período se produjo también un cambio tipológico en las ánforas africanas, que se concreta en la aparición de los grandes contenedores cilíndricos (Keay 35, 36, 55, 56 y 57). Ello implica cambios en la comercialización y quizás en la producción (¿salazones, fruta, aceite?) que desconocemos, y que parecen guardar relación con el cambio tipológico de la sigillata africana D y de las lucernas, así como plantear su relación con la invasión vándala de Africa y las reconversiones económicas que ello pudiera implicar.

En este sentido, además del de Vila-roma (Ted'a 1989), se conoce otro contexto en Tarragona, fechado a finales del siglo V o inicios del VI, situado en la parte alta de la ciudad, en la c/ Merceria, 11, donde se han localizado dos fragmentos de la forma Keay 35 A (Piñol 1995: 202 y 225, fig. 11, núms. 2-3). Recordemos que en Marsella la Keay 35 es el ánfora africana más frecuente en estratos de mediados del siglo $\mathrm{V}$, perdurando durante la segunda mitad de dicho siglo (Bonifay y Piéri 1995: 98). Sin embargo, podría llegar hasta al menos inicios del siglo VI, como lo pueden indicar diferentes hallazgos de Tarragona (Torre de la Audiència y plaza del Rovellat), Pollentia y Cartago (Keay 1984/I: 240). Con respecto a la forma Keay 55, su ausencia en el contexto de la c/ Vila-roma de Tarragona, junto con la presencia de un ejemplar del tipo Keay $55 \mathrm{~A}$ en la Antigua Audiencia (también en Tarragona), en un contexto de la segunda mitad del siglo V (Remolà 2000: 56) demuestran que se trata también de una forma originada en la segunda mitad de dicho siglo, aunque la forma Keay 55 tiene una importante presencia en contextos 


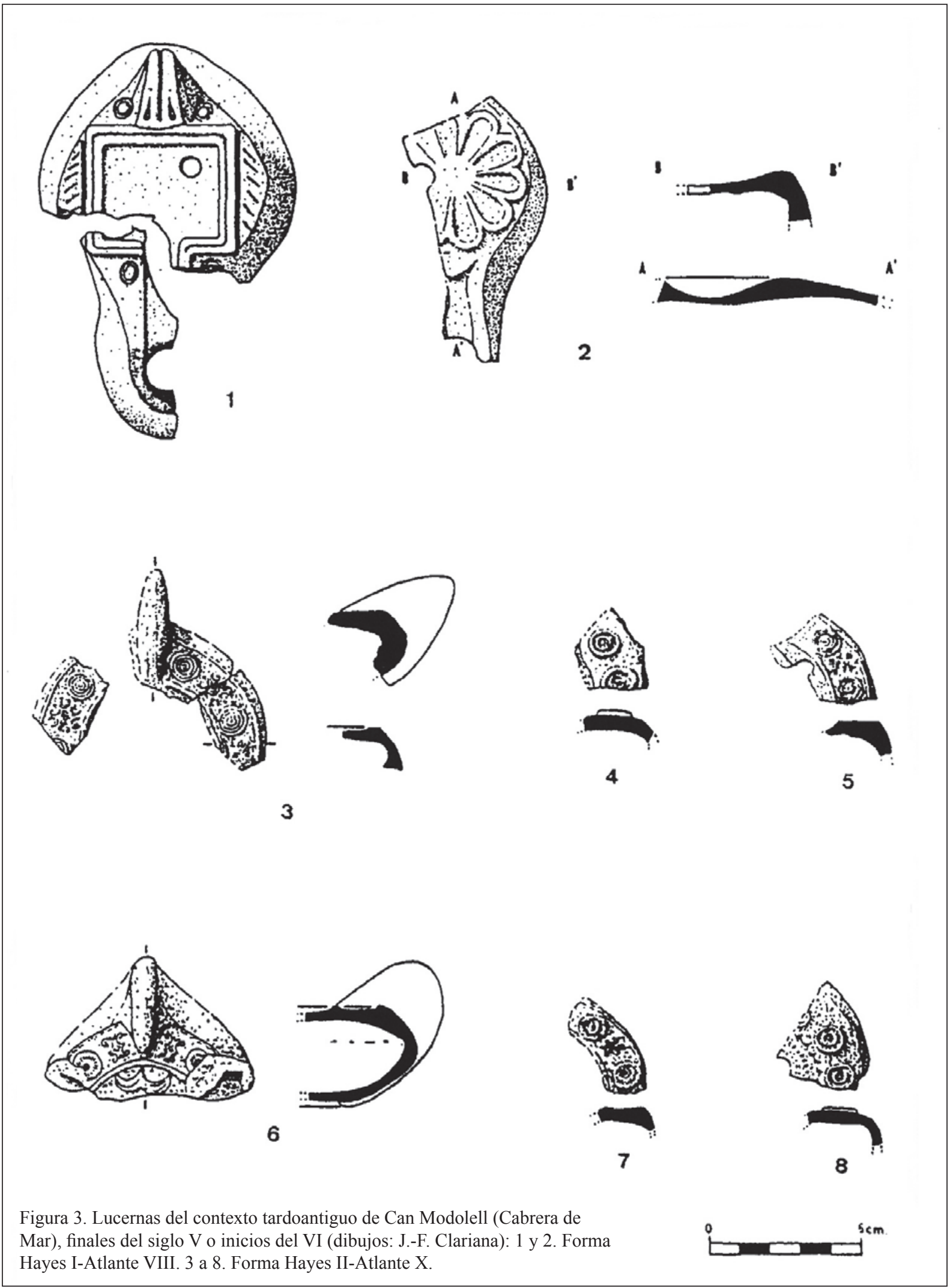


del siglo VI, como se documenta en Marsella (Bonifay y Piéri 1995: 102). Finalmente, las formas Keay 56 y 57 han sido documentadas en el yacimiento de la Solana (Cubelles, Garraf) en un contexto de la segunda mitad del siglo V o ya del VI (Járrega 2007c: 96-97); la ausencia de la forma Keay 57 en la necrópolis del Francolí de Tarragona es un razonable indicio de que se produjo con posterioridad a mediados del siglo $\mathrm{V}$, ya que no hay ánforas posteriores a esta fecha en dicha necrópolis.

Sin embargo, el siglo $\mathrm{V}$ es también el período de auge de las ánforas orientales (especialmente las formas Late Roman Amphora 1, 3 y 4). La distribución, en las costas del Mediterráneo occidental, de las ánforas del tipo Late Roman Amphora 1, que supuestamente transportó aceite de la zona de Antioquía o de Chipre, y las Late Roman Amphora 4, que contuvieron probablemente vino de la zona de Gaza (sin descartar un posible origen egipcio de la producción) es bastante amplia (Reynolds 1995, 80-82). Es difícil precisar si este proceso se produjo desde inicios del siglo $\mathrm{V}$ o ya a mediados de esta centuria, y por lo tanto relacionarlo o no con una posible disminución (en todo caso, breve) del flujo comercial de las ánforas africanas a mediados del siglo $\mathrm{V}$, a causa de la conquista vándala de Cartago. En la c/ Vila-roma de Tarragona las ánforas del Mediterráneo oriental tienen una presencia cuantitativamente importante (Ted'a 1989: 276-299), constituyendo el $25 \%$ del total.

La comercialización de los productos africanos tuvo que estar, por lo menos en buena parte, en manos de los comerciantes procedentes del Mediterráneo oriental, que están bien atestiguados en las fuentes escritas, también en Hispania (García 1972); en este sentido, es interesante la referencia de Procopio (Bellum Vandalicum, XX.2 y XX.4) sobre la abundancia de comerciantes orientales en Cartago en época vándala, que, a modo de quinta columna, colaboraron en la entrada de los bizantinos en Cartago. La actividad de estos mercaderes permitiría explicar la presencia conjunta de las ánforas africanas y de las orientales en las costas hispánicas (García Vargas 2011).

Se constata una presencia bastante significativa de las ánforas sudhispánicas; en el caso del ánfora olearia Dressel 23, la mayoría son variantes tardías, propias del siglo V (Dressel 23 C y D), que se documentan sobre todo en las áreas urbanas, pero también las rurales (Berni 1997, Járrega 1993-2009, Járrega 2000b). También hay que destacar la presencia de las ánforas Almagro 51 A/B - Keay 19 y Almagro 51 C - Keay 23 (Járrega 1993-2009). Si bien en el caso de la forma Dressel 23 queda claro que su contenido fue el aceite bético (lo cual sirve para desmentir la desaparición de estas exportaciones al entrar en crisis la annona imperial), existe el problema del desconocimiento de qué producto o productos se envasaron en las ánforas Keay 19 y 23, así como está por determinar si procedían del Sur de la Lusitania o de la Bética.

Se observa también una importante penetración de las producciones sudhispánicas en el área rural (Can Samarruga, en Palau-Solitar i Plegamans, en el Vallès; El Morer, en Sant Pol de Mar, Maresme; etc.), con porcentajes que oscilan entre el 11\% y el 40\% de las ánforas tardoantiguas (Járrega 1993/2009: 1311-1313) lo cual es significativo de la aún importante comercialización del aceite bético, quizás superior en volumen (en la zona catalana) al de las Dressel 20 altoimperiales. Ello implica la importación de productos como el aceite bético (Dressel 23) en las zonas rurales de Cataluña, a pesar de que posiblemente eran zonas productoras. Habría que preguntarse por qué se produce esta presencia relativamente importante de los productos béticos en las áreas rurales.

La perduración de estas producciones sudhispánicas se alarga hasta la segunda mitad del siglo V, no pareciendo entrar en el siglo VI más que en cantidades poco significativas, y en todo caso limitándose tipológicamente a las Keay 19 y 23, excluyendo la Dressel 23. (Fig. 4)

Hay una evidente capilaridad en la distribución de estas producciones (tanto africanas como orientales y sudhispánicas) en las áreas rurales hacia el interior, como lo indica el caso de la Cova Colomera (Járrega 1990a) en el macizo del Montsec, donde encontramos un ejemplar de ánfora oriental de la forma Late Roman Amphora 4.

La mayor diversificación de los productos importados afecta, lógicamente, a la presencia porcentual de los mismos. Así, en Tarragona las ánforas africanas constituyen el $24,5 \%$, las orientales el $25,5 \%$ y las sudhispánicas el 25\% del total de las ánforas en el yacimiento de la c/ Vila-roma (Ted'a 1989: 316), si bien el 25\% corresponde a otras procedencias o éstas no se conocen. En un contexto de la Antigua Audiencia, también en Tarragona, las ánforas africanas corresponden al 61\%, siendo el resto sudhispánicas, orientales e indeterminadas (Remolà 2000: 56). En el denominado cardo maximus de Iluro (Mataró), las ánforas africanas corresponden al $56 \%$ del total, las sudhispánicas al 23\% y las orientales al 12\% (Cerdà et al. 1997/II: 140); en el conjunto de Iluro, estas ánforas corresponden al 57,2\%, el 36,3\% y el 5,1\% respectivamente (Cela y Revilla 2004: 353), lo que da un porcentaje muy bajo para las orientales.

La diferencia porcentual entre las ánforas africanas y las del Mediterráneo oriental en el siglo de V 


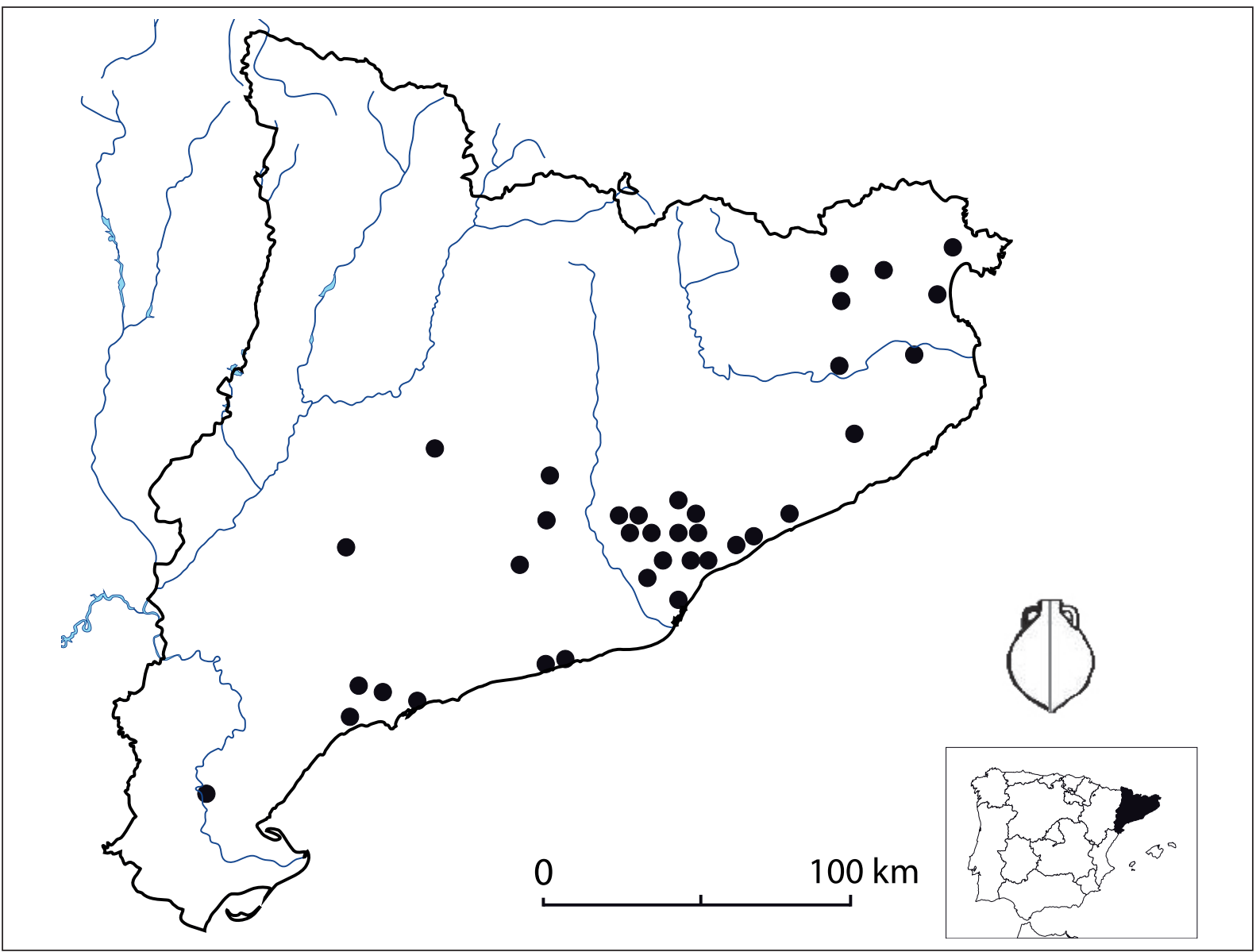

Figura 4. Distribución de las ánforas béticas de la forma Dressel 23 en Cataluña.

han sido un tema discutido. En la zona catalana, Keay (1984, vol II: 428) había supuesto una presencia masiva de las ánforas africanas, mientras que las producciones del Mediterráneo oriental y las sudhispánicas aparecen en cantidades mucho más discretas. Sin embargo, el contexto de la c/ Vila-roma en Tarragona, que fue fechado inicialmente en el segundo cuarto del siglo de $\mathrm{V}$ (Ted'a 1989), aunque más tarde se ha datado en el tercer cuarto de este siglo (Reynolds 1995:281) permite documentar una presencia importante de los productos del Mediterráneo oriental, que constituyen el 25\% de todos los materiales anfóricos (Ted'a 1989: 317). De todas formas, los resultados generales del área catalana pensamos que confirman la valoración inicial de Keay, aunque con matices.

Por otro lado, cabe destacar la importancia de las ánforas sudhispánicas, bastante mejor representadas que en yacimientos franceses e italianos (Reynolds 1995: 176, 179 y 184-186).
En esta fase, grosso modo en la segunda mitad del siglo IV y la primera del V, se alcanza el máximo de volumen de cerámicas importadas tardorromanas en la zona rural. Si bien aparecen en general en menor cantidad que en el período anterior, en algunos casos su presencia es relativamente considerable (el 49,01\% del total en Can Modolell, el 47,36\% en Vilauba, el 34,48\% en el Mas del Catxorro, el 23,07\% en el Camp de la Gruta, el $22,72 \%$ en Barrugat, el $21,66 \%$ en la factoría de Roses y el 13,23\% en Torre Llauder) aunque en otros es más discreta (sólo el 4,76\% en Molins Nous y el 3,77\% en Els Antigons), mientras que en algunos no hay materiales posteriores al siglo IV (Járrega 1993/2009).

La importante presencia de estos materiales en el área rural puede significar tanto el lógico resultado de la difusión de estas cerámicas (que en esta época alcanzan su máxima expansión e intensidad) como que este período es el de mayor vitalidad para los asentamientos 
rurales del área catalana. Pudieron producirse ambas cosas a la vez, o tal vez sólo la primera; sin embargo, lo que sí evidencia este hecho es que los canales de distribución de estas cerámicas ( $\mathrm{y}$, en consecuencia, la relación entre el campo y la ciudad) gozaron de plena normalidad, al igual que en períodos anteriores.

En los núcleos urbanos la situación es más matizable, dada la importancia de conjuntos cerámicos como los del Tinell y la plaza del Rey en Barcelona (Járrega 1993-2009), aunque sin datos estratigráficos por tratarse de excavaciones antiguas, y de la Torre de l'Audiència y la c/ Vila-roma en Tarragona (Keay 1984, Ted'a 1989), donde abundan materiales de mediados y segunda mitad del siglo V y de los siglos VI-VII.

En resumidas cuentas, podemos decir que el siglo $\mathrm{V}$ implica una reestructuración (reflejada en la tipología) de las producciones africanas (tanto vajilla como ánforas) y una diversificación de producciones que corresponde también a una diversificación del mercado, que podemos o no interpretar como resultados de crisis regionales, especialmente en lo que se refiere a la conquista vándala de la provincia romana de Africa.

\section{SIGLO VI}

Actualmente contamos con una serie de contextos arqueológicos, situados en Ampurias (L'Escala, Alt Empordà, Gerona) (Aquilué 1997), la carretera de L'Escala a Ampurias (Llinàs 1997), Mataró (Maresme, Barcelona) (Járrega y Clariana 1994, Cela y Revi1la 2004), Els Mallols (Cerdanyola, Vallès Occidental, Barcelona) (Járrega 2007b), Barcelona (contexto de la plaza del Rey) (Járrega 2005a y 2005b) y La Solana (Cubelles, Garraf, Barcelona) (Barrasetas y Járrega 1997, Járrega 2007c).

Por otro lado, se conocen diversos contextos en la ciudad de Tarragona (Aquilué 1992a, Remolà 2000), tanto en la parte alta de la ciudad (c/ Mercería 11, c/ Misser Sitjes 8-12, pl. Fòrum 1 y 4, c/ Trinquet Vell 4, c/ Trinquet Vell 12, c/ Puig d'en Sitges, 8-12, colegio de Arquitectos) como en la parte baja (c/ Sant Josep, 10), con sigillata africana $\mathrm{C}$ tardía (Hayes 84 similis, tal vez Fulford 27), africana D (formas Hayes 12, 80 A y B, 81, 87 A y C, 91 A/B y C, 94, 99, 110 y 104 A), Late Roman $C$ (Hayes 3 B y C, y 5 B), ánforas africanas (Keay 35 A, 57 B y C, 61 C y 62 A y Q, junto con formas más antiguas), orientales (Late Roman Amphora 1, 2, 3 y 4), así como sudhispánicas (Dressel 23, Almagro 51 A/BKeay 19, Almagro $51 \mathrm{C}$ - Keay 23), que podrían o no ser residuales.
Debemos plantearnos la importancia que pudo tener la conquista bizantina de Cartago en el año 534 y la rivalidad entre visigodos y bizantinos después de la conquista de parte de Hispania por éstos últimos en 552. Es significativa la referencia anteriormente mencionada de Procopio (Bellum Vandalicum, XX.2 y XX.4), quien indica que los numerosos comerciantes orientales que se encontraban instalados en Cartago favorecieron la conquista, constituyendo una suerte de "quinta columna". Aunque tradicionalmente se ha supuesto que esta conquista facilitó e impulsó la comercialización de los productos africanos (Hayes 1972: 426), se ha indicado también que de hecho la conquista fue muy negativa para el comercio y marcó el principio de un período de crisis en Cartago (Keay 1984/II: 428).

Después de la conquista bizantina del Sudeste de Hispania, se ha sugerido que el comercio y, en concreto, la llegada de la cerámica africana a las zonas bajo dominio visigodo experimentó dificultades debido a la mencionada rivalidad entre visigodos $\mathrm{y}$ bizantinos; por esta razón, se ha sugerido que como resultado se produjo un total corte de las importaciones africanas en las áreas costeras hispánicas al Norte de la provincia bizantina (Keay 1984/II: 428, Nieto 1984: 547). Sin embargo, sabemos hoy que esta hipótesis es incorrecta (Járrega 1987 y 2000). En todo caso, sí que podría haberse producido una disminución en el volumen de las importaciones, pero no una ruptura total de las mismas.

Como avanzamos ya hace algunos años (Járrega 1987), la evidencia considerada permite demostrar que, en contra de lo que se había asumido, no existió ningún corte en la difusión de la cerámica africana en el Nordeste de la Península ni con la conquista de Cartago por los bizantinos ni cuando éstos ocuparon una parte de Hispania (Járrega 1987 y 2000). Por el contrario, las formas más tardías de la sigillata africana (Hayes 104 C, 105 a 109, 101 y 91 D) se documentan en las zonas peninsulares situadas tanto dentro como fuera de la provincia bizantina. De todos modos, en Cataluña aparecen en muy pocas cantidades, en comparación con su abundante presencia en contextos del siglo $\mathrm{V}$ o de la primera mitad del VI. En La Solana de Cubelles, la sigillata africana D constituye solamente el 3\% del total de las importaciones, mientras que las ánforas africanas corresponden el 91\% de las mismas (Barrasetas y Járrega 1997, Járrega 2007c: 108). En el Nordeste de Cataluña la presencia de la sigillata africana decae en la segunda mitad del siglo VI en un 98,34\% (Nieto 1993: 204) mientras que en Tarragona lo hace en un $85,88 \%$ (Aquilué 1992). 
Con respecto a la sigillata africana D, se documenta durante la primera mitad del siglo VI una continuidad (e, incluso, quizás un incremento) en la circulación de las formas de sigillata africana propias de la segunda mitad de la centuria anterior (formas Hayes 91 C, 96, 97 y 99, así como decoración del estilo E-2), lo cual podemos relacionar con la actividad económica desarrollada en época del reino vándalo. Sin embargo, se produjo una rarificación en las importaciones a partir de mediados del siglo VI, precisamente cuando aparecieron formas nuevas (Hayes 103 y 104) coincidiendo aproximadamente en el tiempo con la conquista bizantina, que podría haber sido la causante de esta disminución. Recordemos que, por ejemplo, la forma Hayes 104 B no se documenta en Marsella antes de mediados del siglo VI (Bonifay et al. 1998: 365), por lo que parece que se trata de una forma de cronología relativamente avanzada.

La mayor parte de los materiales de este período presentan una concentración en las áreas urbanas (Gerona, Barcelona, Tarragona, Tortosa), con pocos ejemplares en las áreas rurales, como lo reflejan los hallazgos de los yacimientos de la Timba del Castellot (Riudoms, Baix Camp); Barrugat, cerca de Tortosa (junto al río Ebro) y Els Mallols (Cerdanyola, Vallès Occidental), donde documentamos la forma Hayes 103. La forma más abundante, la Hayes $91 \mathrm{C}$, que actualmente podemos fechar en pleno siglo VI (Fulford y Peacock 1984: 65 y 67, Reynolds 1995: 151) se documenta en Vilauba (Camós, Pla de 1'Estany), Can Modolell (Cabrera de Mar, Maresme), Torre Llauder (Mataró, Maresme), L'Aiguacuit (Terraza, Vallès Occidental) y Maians (Castellfollit Boix, Bages) (Járrega 1993-2009).

En general, hoy por hoy no podemos atribuir los materiales encontrados a un centro de producción concreto, aunque esperamos que los progresos en la investigación nos permitirán hacerlo. Sin embargo, un punzón del taller de Sidi Marzouk Tounsi, en el Túnez central, que representa un crismón, ha sido identificado en Tarragona (Aquilué 2003).

Debemos considerar una posible continuidad durante la primera mitad del siglo VI en la llegada de la Late Roman $C$, siempre en cantidades discretas. Sin embargo, la falta de contextos claros de esta época nos impide precisarlo. Por otra parte, en este momento han desaparecido ya del mercado la sigillata hispánica tardía y la "D.S.P.", absolutamente ausentes en el contexto de la carretera de Ampurias estudiado por Llinàs (1997: 164-166) y prácticamente ausente también en los contextos del siglo VI de la Solana de Cubelles (Barrasetas y Járrega 1997, Járrega 2007c) así como en Tarragona, donde en un contexto de amortización fechado a finales del siglo V o inicios del VI, se han documentado sólo dos fragmentos, correspondientes a las formas Rigoir 1 y 6 (Piñol 1995: 198-199). Se puede hablar, por lo tanto y a pesar de la disminución, de un monopolio de la sigillata africana con respecto a la vajilla de mesa.

En cuanto a las lucernas, aunque en poca cantidad, se confirma la desaparición de la forma Hayes I - Atlante VIII y su total sustitución por la Hayes II - Atlante $\mathrm{X}$, evidente en contextos de finales del siglo VI o inicios del VII, como el de la plaza del Rey de Barcelona (Járrega 2005b: 239, 246, lám. 5). Sin embargo, estas lámparas son muy poco abundantes; en el yacimiento de Els Mallols (Cerdanyola) hay tan sólo dos fragmentos, de los cuales tan sólo uno puede identificarse con seguridad con la forma Hayes II - Atlante X (Járrega 2007b: 124, fig. 7.3.8 y 126), y en La Solana (Cubelles) no hay ninguno.

En este período es mucho mayor la proporción de las ánforas africanas en relación con las orientales, como se documenta en el contexto de la Torre de la Audiencia, en Tarragona, donde el 86\% de las ánforas corresponden a talleres situados en el Mediterráneo occidental, de los cuales las ánforas africanas constituyen el 90\%, del que a su vez el 68\% corresponde a la forma Keay 62 (Remolà 2000: 60). En el yacimiento de Els Mallols (Cerdanyola), las formas africanas que se documentan son las Keay 26 o spatheia, así como las Keay 55, 61 y 62; asimismo, se documentan en poca cantidad ánforas orientales de las formas Late Roman Amphora 1, 4 y qiuzás 3, ánforas baleares del tipo Keay 79, ánforas sudhispánicas de las formas Dressel 23 y Almagro 61 A/B-Keay 19 (probablemente residuales), así como posibles ánforas globulares (Járrega 2007b: 126-137). Por lo tanto, este yacimiento proporciona unos materiales datados básicamente en el siglo VI, con una perduración en el VII.

La desaparición en el mercado de los productos envasados en ánforas sudhispánicas, que no superan (si es que llegan) los primeros años del siglo VI, deja el mercado prácticamente limitado a los productos africanos y orientales. En relación con estas últimas, constatamos una continuidad tipológica, sólo con variaciones formales internas (caso de las Late Roman Amphora 1 y 4).

Las ánforas africanas siguen con el formato de grandes ánforas cilíndricas pero con la aparición de una nueva forma standard que se documenta en grandes cantidades: la Keay 62, claramente mayoritaria en contextos de pleno siglo VI, como se puede comprobar, por ejemplo, en la necrópolis de la plaza del Rey de Barcelona (Járrega 2005a). Este contexto creemos que hay que fecharlo a finales del siglo VI o inicios del VII, por 
su asociación con una iglesia cuyos niveles fundacionales han proporcionado fragmentos de las formas Hayes 91 D y 105 de la sigillata africana D, mientras que el ánfora de la forma Keay 61, típica del siglo VII, está ausente en la necrópolis. Hacia finales del siglo VI apareció la forma Keay 61, que deriva claramente de la 62; se había indicado que podría aparecer en el contexto del siglo V de la c/ Vila-roma, en Tarragona (Ted'a 1989: 265-266), pero ya Keay (1984) remarcó su ausencia en la necrópolis del Francolí en Tarragona, así como en algunos contextos de mediados del siglo $\mathrm{V}$ de Roma, Nápoles y Cartago. Los estudios de Bonifay (2004: 137-138) han permitido aclarar la confusión tipológica con otros productos, que había hecho parecer esta forma más antigua de lo que en realidad era. Su ausencia en el contexto de la plaza del Rey, datable hacia finales del siglo VI o inicios del VII y donde aparece mayoritariamente la forma Keay 62, es otro indicio de que esta forma es propia del siglo VII. (Fig. 5)

En la segunda mitad del siglo VI se fecha la aparición de las anforillas más pequeñas del tipo spatheia (o Keay 26), de procedencia aparentemente africana y destinadas a envasar salazones y/o otros productos (salsas). Por otra parte, durante el siglo VI llegó, de forma muy esporádica, un producto itálico (probablemente vino) envasado en la forma Keay 52 (Keay 1984/I: 267-268).

La distribución de las importaciones es básicamente costera y urbana, con una rarificación en las zonas rurales conforme avanza el siglo VI; sin embargo, hay una pervivencia en la distribución en las áreas rurales próximas a las ciudades (villas de Els Antigons y Barrugat, mut cerca de Tarragona y Tortosa respectivamente), e incluso una penetración muy esporádica en el interior, cómo lo indica el hallazgo de ánforas de las formas Keay 55 y 62 en el yacimiento del Roc d'Enclar, en Andorra (Llovera et al. 1997).

Se documenta asimismo una discreta distribución de anforillas de origen ibicenco (Reynolds 1995: 6364 y 66-67), con una cierta complejidad tipológica, ya que los tipos Keay 70 y 79 no son fácilmente diferenciables entre sí, pudiendo corresponder a la misma forma, que puede presentar variaciones. Su pequeño tamaño permite suponer que se envasaba alguna producción lujosa (¿vino de calidad?), si no es que se trata simplemente de tinajas. Estas producciones tienen una presencia bastante discreta a lo largo de la costa, en algunos contextos de la época, como el de la plaza del Rey de Barcelona, datable hacia finales del siglo VI (Járrega 2005a-b) o los del denominado cardo maximus de Iluro, hoy Mataró (Cela y Revilla 2004).
Es muy destacable la aparición de una anforilla, detectada por primera vez en el yacimiento de La Solana (Cubelles), que se constata a lo largo de la costa central y Sur de Cataluña (Iluro, Barcino y Tarraco; cf. Járrega 2007a). Se trata de una producción de origen indeterminado, pero probablemente localizado en esta zona. El producto que se envasaba es también indeterminado (¿vino?). Su difusión es todavía desconocida, pero se ha documentado en contextos de mediados del siglo VI en La Solana (Cubelles) (Barrasetas y Járrega 1997, Járrega 2007c), Mataró (Cela y Revilla 2004), Els Mallols (Cerdanyola, Vallès Occidental, Járrega 2007b: 134-137), Els Munts (Altafulla; $c f$. Sada et al. 2005: 110) y Els Antigons (Reus). Sin embargo, como en el caso de las producciones ibicencas, podría tratarse simplemente de grandes tinajas, como lo puede hacer pensar su utilización en una fontana pública de Tarraco (Remolà y Pociña 2005: 64), ciudad en la que se documenta también en un contexto de la parte alta de la ciudad, en la plaza de Els Sedassos, fechado a partir de la segunda mitad del siglo VI (Remolà 2000: 237).

En resumidas cuentas, podemos afirmar que se constata una presencia mayoritaria de las producciones africanas (sigillata africana D, ánforas y en menor medida, lucernas), pero en cantidades discretas a partir de mediados del siglo VI, con una clara distribución en las zonas costeras y urbanas, pero también con una penetración esporádica en zonas rurales y del interior. Se documenta una presencia preponderante de las ánforas africanas de la forma Keay 62. Por otra parte, hay una continuidad en la llegada de las producciones orientales, pero en franca minoría en relación con las africanas, y una desaparición de las producciones vasculares gálicas e hispánicas.

\section{SIGLO VII}

Los contextos y hallazgos de este período se fechan en general entre la segunda mitad del siglo de VI y la primera del VII. Hasta este momento, los contextos de esta cronología aparecen limitados a la costa catalana. Éstos se documentan principalmente en los núcleos urbanos (Ampurias, Mataró, Badalona, Barcelona, Tarragona, así como quizás la Ciutadella de Roses) aunque también en los núcleos rurales (Puig Rom, Camp de la Gruta, Nostra Senyora de Sales, La Solana, Els Antigons), especialmente por la presencia de la forma Hayes $91 \mathrm{D}$ de la sigillata africana D (los contextos bien conocidos no permiten fechar esta forma antes del siglo de VII o, como muy tarde, el final del VI) y de las ánforas africanas de las formas Keay 61 y 62. 


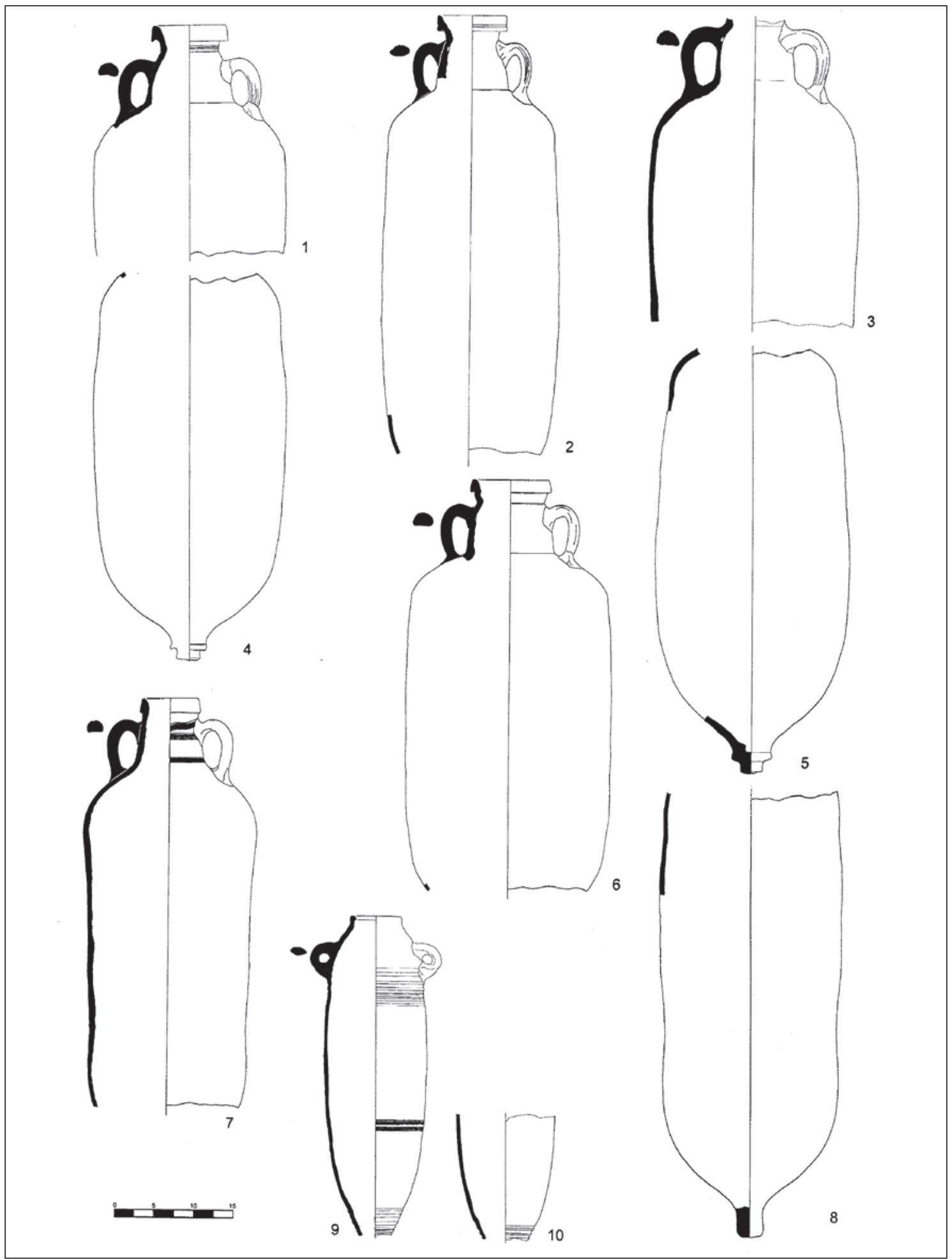

Figura 5. Ánforas del contexto tardoantiguo de la plaza del Rey (Barcelona), finales del siglo VI o inicios del VII (dibujos: Museo de Historia de Barcelona). 1, 2 y 6. Ánfora africana, forma Keay 62 A. 3, 4 y 5. Ánfora africana, forma Keay 62. 7. Ánfora africana, forma Keay 60. 8. Ánfora africana, forma indeterminada. 9. Ánfora del Mediterráneo oriental, forma Late Roman Amphora 4 C. 10. Ánfora del Mediterráneo oriental, forma Late Roman Amphora 4. 
De entre estos contextos podemos destacar el de la Torre de la Audiencia de Tarragona (el denominado "Torre de la Audiencia" 2), que corresponde a un vertedero excavado sin los criterios científicos actuales, aunque cuenta con un buen número de materiales de los siglos IV y V (evidentemente residuales), pero también de finales del siglo VI y el VII (Keay 1984/I: $17-$ 19, 56, Aquilué 1992a, Remolà 2000: 58-60). En este yacimiento se han documentado, junto con cerámicas más antiguas, fragmentos de sigillata africana D (Hayes 91 D, 101, 103 B, 104 A, B y C, 105, 106, 107 y 109), junto con ánforas africanas (Keay 57, 59, 61, 62, 63, 64) y orientales (Late Roman Amphora 1, 2, 3, 4 y 5/6, y Keay 67). También corresponden a este período las ánforas orientales (formas Late Roman Amphora 1 tardía, Late Roman Amphora 4 C y Keay 67) halladas en la necrópolis septentrional de Tarraco, situada al pie de la montaña de la Oliva (Remolà 2000: 108-109), lo que como contexto material resulta poco significativo por su escasez, aunque es interesante para el conocimiento de la topografía funeraria de la ciudad en esta época.

En la misma Tarragona se constatan también algunos contextos en la parte alta de la ciudad (plaza del Pa1lol, plaza del Fòrum 2 y 3, plaza dels Sedassos) y en el área portuaria (c/ Sant Miquel 33, PERI-2), con presencia de sigillata africana D (Hayes 91 D, 99 C, 104 B y C, 105, 106, 107 y 109, junto con otras anteriores como las Hayes 91 C, 99 y 104 A), Late Roman C (Hayes 3 C), y ánforas africanas (Keay 8 A, 56 B, 61 C, 62 A), orientales (Late Roman Amphora 1, 2, 3 y 4), además de ánforas globulares (Aquilué 1992a, Remolà 2000). Aunque hay que tener en cuenta la presencia de materiales claramente residuales (como en el caso de las ánforas sudhispánicas), los materiales más recientes, contemporáneos de la formación de los contextos, nos acreditan su atribución al siglo VI avanzado y al VII.

En Iluro (Mataró) se han documentado algunas fosas cuyos rellenos pueden datarse a finales del siglo VI o inicios del siglo VII, como en el caso documentado en la bajada de Les Espenyes, donde se documentó sigillata africana D de la forma Hayes 104 C, ánfora africana de la forma Keay $56 \mathrm{~B}$ y un plato de posible sigillata egipcia B (Járrega y Clariana 1994a-b). Otros contextos similares documentados en los últimos años en la antigua Iluro (Mataró) presentan un panorama similar, con presencia de las formas Hayes 91 D, 101 y 109, junto con abundantes materiales residuales (Cela y Revilla 2004: 360). (Fig. 6)

En cuanto a la vecina Baetulo (Badalona), unas excavaciones efectuadas en la plaza de Font y Cussó dieron como resultado el hallazgo de unos niveles constructivos a los que se asocia sigillata africana D de las formas Hayes 103 A, 104 A y C, 91 C y 99, entre otras, además de al parecer Hayes 105 (Comas y Padrós 1997). El hecho de que en la publicación correspondiente no se ilustre la forma Hayes 105 dificulta la comprobación de su presencia; además, la gran abundancia de material residual disminuye el valor de este contexto, donde aparecen en abundancia materiales de finales del siglo V e inicios del VI. Sin embargo, la forma Hayes 104 C sí que apunta a una datación de al menos segunda mitad del siglo VI, aunque no podamos confirmar la presencia de la forma Hayes 105.

El hallazgo de una moneda del rey visigodo Akhila en el poblado de Puig Rom (Nolla y Casas 1997, Palol 2004) permite considerar dicho hábitat activo durante la segunda mitad del siglo de VII, aunque es posible que estuviese en actividad a inicios del siglo. Por esta razón, no es posible determinar si las ánforas halladas en este establecimiento corresponden a la primera o a la segunda mitad del siglo de VII. Por otro lado, la presencia de una lucerna africana de la forma Hayes II también en Puig Rom confirma la continuidad de estas importaciones en el siglo VII, como se demuestra con los hallazgos de Cartagena (Ramallo et al. 1997: 206-207).

Aunque la disminución es muy importante, merece destacarse la presencia de formas de la sigillata africana D datables en el siglo VII (Hayes 91 D, 104 C, 105, 107) en Barcino, Tarraco y Dertosa, así como en Sant Martí d'Empúries e Iluro, aunque esporádicamente aparecen todavía en zonas rurales próximas a las ciudades (Ciutadella de Roses, Camp de la Gruta, Puig Rodon, Ntra. Sra. de Sales, Centcelles, Els Antigons; cf. Járrega 1993/2009). La presencia porcentual de estas sigillatae africanas de la última fase es muy escasa, prácticamente irrisoria, en relación con el resto de $s i$ gillatae africanas y de cerámicas tardorromanas en general, y se reduce exclusivamente a la forma Hayes 91 D en los yacimientos rurales. En Els Mallols (Cerdanyola), aunque la mayoría de los materiales corresponda al siglo VII, la presencia de ánforas Keay 61 y posibles ánforas globulares permite documentar la presencia de importaciones en el siglo VII (Járrega 2007b: 126-127, 130-131 y 133-135). En el mencionado yacimiento de Puig Rom (Roses, Girona) se ha hallado solamente un fragmento informe de sigillata africana D (Nolla y Casas 1997), mientras que se documentan ánforas africanas, al parecer en cierta abundancia.

Estos ejemplares de sigillata africana D siempre aparecen en pocas cantidades, lo cual contrasta con la 
relativa abundancia en que se encuentran en Cartagena, cuando en Cataluña formas como la Hayes 108 o la 109 son prácticamente ausentes (Járrega 1991: 52 y 76, Járrega 1993-2009). Concretamente en el área catalana la sigillata africana D presenta, con posterioridad a mediados del siglo VI d.C., una fortísima reducción que oscila entre el $85 \%$ y el 98\%, como indican los hallazgos de Tarragona y Roses (Aquilué 1992a, Nieto 1993: 204). Quizás podría haberse acentuado la rivalidad entre visigodos y bizantinos durante esta centuria (Cartagena fue conquistada por el rey visigodo Suintila hacia el año 623), pero eso no sería suficiente como para cortar totalmente su comercialización en Cataluña.

En El-Mahrine (Túnez) se constata la producción de sigillata hasta los años 640-660, es decir, coincidiendo con la ocupación musulmana (Mackensen 1993) ¿Llegaron a Hispania importaciones de África hasta el último momento de producción? Ello parece posible para la provincia bizantina, pero es difícil de constatar más al Norte. Sin embargo, otros talleres de Túnez no superan el siglo VI, por lo cual se puede plantear también una disminución en las áreas de producción.

Con respecto a las lucernas, es difícil constatar su presencia al faltar contextos bien fechados (y teniendo en cuenta que ya no eran muy abundantes en el siglo VI), pero el hallazgo de un fragmento de la forma Hayes II - Atlante X en el poblado visigótico de Puig Rom (Roses), acompañado por ánforas y en ausencia ya de sigillata (Nolla y Casas 1997), permite documentar la circulación de estas lámparas todavía en el siglo VII.

Todos estos datos demuestran que, aunque las importaciones de la cerámica fina africana continuaron llegando a los puertos nororientales de Hispania durante la segunda mitad del siglo de VI e inicios del VII, lo hicieron en cantidades reducidas. Sin embargo, las ánforas (especialmente africanas) continuaron llegando en cantidades considerables, como parece desprenderse de los hallazgos de Puig Rom. Los resultados proporcionados por las ánforas permiten constatar que la costa catalana continuó recibiendo importaciones de materiales africanos durante el siglo VII.

A pesar de la importante disminución constatada en este siglo, las ánforas continuaron llegando en cierta abundancia a las áreas urbanas, como indica la probable continuidad durante el siglo VII de la forma Keay 62 y la distribución de los spatheia y de la Keay 61 (Barcino, Tarraco); esta última forma, propia de contextos del siglo VII (Bonifay 2004: 139-141) se encuentra también, además de en estas ciudades, en el Puig de les Sorres (Viladamat), Roses, Terrassa, Cirera y Caputxins (Mataró) (Járrega 1993/2009).
Un ejemplar de la forma Keay 36 B fue hallado en la necrópolis de la Ciutadella de Roses que se asienta sobre las ruinas de la factoría de salazón del siglo IV a la que antes nos hemos referido (Nolla 1984), y que no pudo ser abandonada antes de finales del siglo VI, puesto que entre los materiales de sus estratos de colmatación figura un fragmento de sigillata africana $\mathrm{D}$ de la forma Hayes 91 D. Ello es un claro indicio de que la forma Keay 36 B corresponde al siglo VI avanzado o ya al VII. Por otro lado, las ánforas de la forma Keay 61 A y B que se reutilizaron en la bóveda de la iglesia de Santa María en Terrassa (Keay 1984/I: 92, fig. 32, núms. 2 y 3; 306, fig. 132, núm. 1; 307, fig. 133, núm. $1,303-305)$ pueden datarse con toda probabilidad, en coherencia con lo que hoy sabemos sobre la evolución de la citada iglesia (García et al. 2009), en la segunda mitad entrada del siglo VI o a inicios del s. VII d.C.

Las ánforas del siglo VII presentan una distribución mayoritaria en las áreas urbanas, pero también aparecen esporádicamente en las zonas rurales. Eso se puede deducir de su presencia en el poblado de Puig Rom (formas Keay 61 y 62), interesante por el hallazgo de una lucerna de la forma Hayes II - Atlante X y la práctica ausencia de sigillata (Nolla y Casas 1997), así como el spatheion encontrado en la iglesia de Sant Vicenç de Rus (Castellar de n'Hug, Berguedà; $c f$. López et al. 1997: 66, 81, lám. XI.6), que indica una penetración hacia el interior. Esta penetración fue sin duda ocasional, teniendo en cuenta los datos negativos con respecto a importaciones del poblado de Vilaclara (Castellfollit del Boix, Bages), fechado en el siglo VII por la técnica del carbono 14 (Enrich et al. 1995), y que no presenta ninguna cerámica de importación.

La distribución de estos materiales es casi siempre costera. Sin embargo, algunas excepciones, como el spatheion localizado en Sant Vicenç de Rus, permiten documentar una capacidad esporádica de penetración de las importaciones hacia el interior en los siglos de VI y de VII.

Por otra parte, no se puede documentar con seguridad la posible pervivencia de producciones aparentemente autóctonas como el "tipo la Solana", similar a las ánforas de fondo umbilicado del tipo Castrum Perti $\mathrm{u}$ otros productos como los localizados en la Crypta Balbi de Roma (Murialdo 1996, 2001a-b, Saguì 1998: 315-317), de probable origen africano y bien fechados en el siglo VII, que llegaron (al parecer en poca cantidad) a las costas hispánicas. En San Peyre (Languedoc) se han documentado algunas ánforas globulares (Paroli et al. 1996), así como en Valencia (Pascual et al. 2003: 75 , fig. 5) que habría que revisar con el fin de ver con 
Figura 6. Cerámicas del contexto tardoantiguo de la calle de Les Espenyes (Mataró) (dibujos: J.-F. Clariana). 1. Sigillata africana D, forma Hayes 104 B. 2. Sigillata africana D, forma Hayes $104 \mathrm{C}$. 3. Posible sigillata egipcia B, forma Hayes 1972, fig. 88 b/c. 4 . Borde, cuello y asas de un ánfora africana, forma Keay 56. 5. Cuerpo y base de ánfora africana, acaso también de la forma Keay 56.

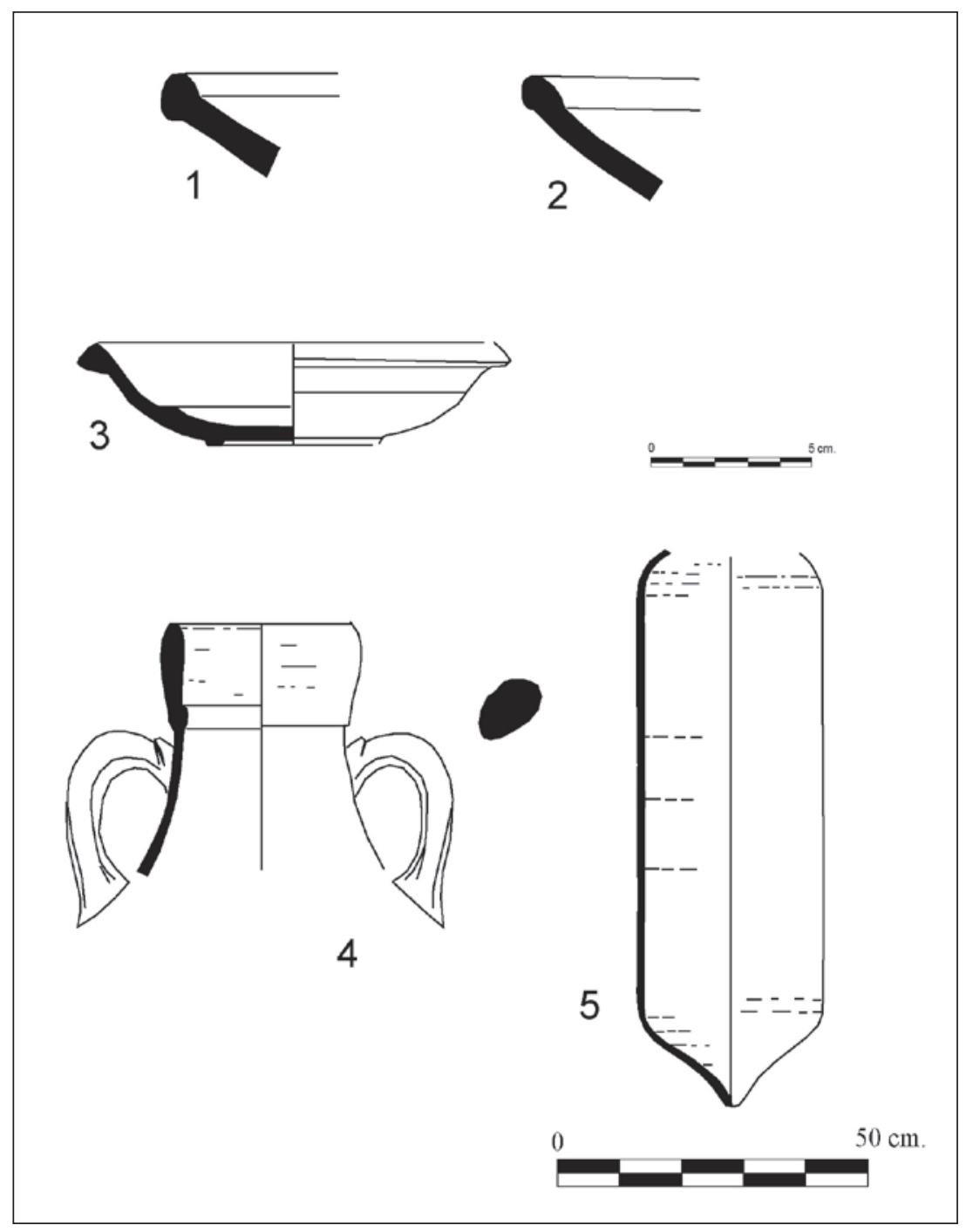

cuál de los dos conjuntos (el más tardío documentado en Italia, o el hispánico del siglo VI) se relacionan. En Cataluña aparecen en Tarragona (Remolà 2000: 164, fig. 46/3-5; 168), Els Mallols (Cerdanyola, Vallès Occidental (Járrega 2007b: 133-135) y Barcelona (Albert Martín, comunicación personal). A estas producciones puede atribuirse un fragmento hallado en el poblado visigótico de Puig Rom, identificado inicialmente como un ánfora oriental del tipo Yassi Ada 2 (Nolla y Casas 1997: 11 y 19, fig. 8.13), lo que cuadra bien con la cronología de este poblado, fechado en pleno siglo VII.

Desgraciadamente, tenemos muy pocos datos que nos permitan estudiar el fin de estas importaciones, pero podemos suponer que hubo una rarificación y un contraste con la provincia bizantina que se podría deber en parte a la rivalidad entre la misma y el reino visigodo, pero esto no explica el final de la comercialización, que quizás llegara hasta el cese de la producción con la conquista islámica de Cartago en 698 (la invasión de África había empezado en 669-670), como propusieron Carandini y Tortorella (Atlante 1981:15). Sin embargo, el fin de las importaciones se podría explicar también por otros factores internos, como la disminución de centros productores en África a partir de la segunda mitad del siglo VI y el progresivo aumento de cerámicas elaboradas a torno lento en la costa hispánica (Gutiérrez 1988, Macías 1999). Ello representa la aparición de una nueva cultura en la elaboración de los alimentos, que afecta a su presentación en la mesa y a su consumo (Aquilué 2003), y que pudieron haber hecho menos necesaria la adquisición de cerámicas de importación. Evidentemente, el tema del contenido de 
las ánforas y su sustitución por productos locales (o por otro tipo de envases) es otra cuestión.

Por lo tanto, la ausencia de cerámicas de tipo romano no significa en absoluto que no hubiese contactos comerciales durante los siglos VII-VIII, como lo indican la llegada de objetos litúrgicos de bronce procedentes del Mediterráneo oriental y las influencias orientales en los modelos arquitectónicos religiosos (Aquilué 2003). También se puede aducir la presencia de mercaderes orientales en Mérida, incluso haciendo obispo a uno de ellos (García 1972), en un momento en que no se detectan importaciones cerámicas en este lugar.

\section{CONCLUSIONES}

a) Durante el siglo IV se documenta una clara superioridad de las producciones africanas (sigillata africana C tardía y D, ánforas y, en menor grado, lucernas) con una concurrencia más pequeña de los productos sudispánicos (ánforas de aceite y salazón). La proporción de estos productos es similar en los yacimientos urbanos y rurales, y por esta razón podemos concluir que no existió ninguna ruptura en la relación comercial entre la ciudad y el campo.

b) La primera mitad del siglo $\mathrm{V}$ supuso una continuidad con la situación anterior, aunque con una mayor presencia de ánforas del Mediterráneo oriental, y la aparición de nuevos productos, como la denominada "D.S.P.", la terra sigillata hispánica tardía (originada en el siglo IV) y la Late Roman $C$ - Phoacean Red Slip ware, que tuvieron su máxima difusión en esta época. Es posible que la invasión vándala de Cartago en 439 pudiese causar algunos cambios en la comercialización de los materiales africanos, pero en la segunda mitad del siglo V, el reforzamiento político del reino vándalo debió comportar algunos cambios tipológicos importantes en los productos africanos (tanto en la sigillata africana D como en las ánforas) y un nuevo impulso a su comercialización.

c) Durante la segunda mitad del siglo VI y la primera mitad del VII (y quizás también durante la segunda mitad) continuó la llegada de cerámicas importadas que procedían muy especialmente de la zona tunecina y, en cantidades más pequeñas, del Este mediterráneo.

d) La sigillata africana experimentó un precipitado declive cuantitativo en este período, pero no desaparece, por lo menos hasta inicios del s. VII. Sin embargo, se documenta una continuidad y hasta acaso un aumento considerable de la producción anfórica africana, por lo que no se puede admitir la hipótesis que proponía el cese de las importaciones a mediados del siglo de VI. Por otra parte, una continuidad (hasta ahora no valorable desde el punto de vista cuantitativo) en la llegada de lucernas africanas se produjo por lo menos durante la primera mitad del s. VII, como demuestran los hallazgos realizados en Cartagena y Puig Rom.

e) Por lo tanto, la rivalidad política entre visigodos y bizantinos no se tradujo en una desaparición del comercio entre la Península Ibérica y el norte de África, si bien parece claro que se produjo una importante disminución de los productos africanos al norte de la provincia bizantina. La causa (o las causas) del final de la llegada de las importaciones mediterráneas a las costas hispánicas no se puede determinar, pero quizás pudo no haber afectado a los centros consumidores sino a los productores, y podría deberse a la invasión islámica del norte de África, como se ha asumido tradicionalmente.

f) Las importaciones anfóricas documentadas en los contextos de los siglos de VI y VII son casi en su totalidad africanas. Sin embargo, se detecta una continuidad (aunque disminuida) en la llegada de productos del Mediterráneo oriental, especialmente del tipo Late Roman Amphora 1. Por otro lado, parece documentarse la llegada de algunas ánforas de perfil globular (Puig Rom, Els Mallols, Barcelona y Tarragona), aunque hasta ahora tenemos pocos datos referentes al área estudiada.

g) Los hallazgos de cerámica importada en Cataluña durante la segunda mitad del siglo VI y el VII se limitan básicamente a las zonas costeras, y se centran especialmente en los núcleos urbanos, pero también llegan los establecimientos rurales cercanos a los mismos. Sin embargo, algunos hallazgos (como los de Sant Vicenç de Rus y el Roc d'Enclar) permiten documentar la llegada esporádica de estas importaciones en áreas geográficas situadas en el interior.

\section{AGRADECIMIENTOS}

Este trabajo ha sido llevado a cabo con en el marco del proyecto de I+D Amphorae ex Hispania. Paisajes de producción y consumo, financiado por el Ministerio de Ciencia e Innovación (código: HAR2011-28244). 


\section{BIBLIOGRAFÍA}

Abascal, J.M. (1986): La cerámica pintada romana de tradición indígena en la Península Ibérica. Centros de producción, comercio, tipología. Alicante, Universidad de Alicante.

Alarcão, J. y Mayet, F. (eds.) (1990): As ánforas lusitanas. Tipologia, produção, comércio (actas da mesa-redonda de Conimbriga em 13 e 14 Outubro 1988). París, De Boccard.

Álvarez, N.; Ballester, C.; Carrión, Y.; Grau, E.; Pascual, G.; Pérez, G.; Rivera, A. y Rodríguez, C.G. (2005): "L'àrea productiva d'un edifici del fòrum de Valentia al Baix Imperi (segles IV-V)", en VI Reunió d'Arqueologia Cristiana Hispànica. Les ciutats tardoantigues d'Hispania: cristianització i topografia, pp. 251-260. Barcelona, Institut d'Estudis Catalans.

Amante, M. y Pérez, M.A. (1995): “Cerámicas tardías de producción egipcia en Carthago Nova”, Antigüedad y Cristianismo XII, pp. 521-532. Murcia, Universidad de Murcia.

Anselmino, L. (1986): "Le lucerne tardoantiche: produzione e cronologia", en A. Giardina (ed.), Società romana e impero tardoantico vol. III, pp. 227-240. Bari, Laterza.

Aquilué, X. (1987): Las cerámicas africanas de la ciudad romana de Baetulo (Hispania Tarraconensis). BAR International series 337. Oxford, Archaeopress.

Aquilué, X. (1992a): Las cerámicas de producción africana procedentes de la colonia Iulia Urbs Triumphalis Tarraco (micro-ficha). Barcelona, Universitat de Barcelona.

Aquilué, X. (1992b): “Comentaris entorn la presència de les ceràmiques de producció africana a Tàrraco", en Miscel.lània arqueolòica a Josep M. Recasens, pp. 25-33. Tarragona, El Mèdol.

Aquilué, X. (1997): “Anàlisi comparativa de contextos ceràmics d'època tardo-romana (segles V-VI)", en Contextos ceràmics d'època romana tardana $i$ de l'alta edat mitjana (segles IV-X). Arqueomediterrània 2: 83-100.

Aquilué, X. (2003): "Estado actual de la investigación de la Terra Sigillata Africana en la Península Ibérica en los siglos VI-VII", en L. Caballero, P. Mateos y M. Retuerce (eds.), Cerámicas tardorromanas y altomedievales en la Península Ibérica. Anejos de Archivo Español de Arqueología XXVIII, pp. 11-20. Madrid, CSIC.

Arce, J. (1982): El último siglo de la España romana: 284-409. Madrid, Alianza Editorial.
Arqueociència S.C.P. (1995): "Excavacions a la perllongació de l'A-19, en M. Prevosti et al. (coords.), Autopistas i Arqueologia. Memòria de les excavacions en la prolongació de l'autopista A-19", pp. 125-235. Barcelona, Autopistas C.E.SA. y Generalitat de Catalunya.

Atlante (1981): Atlante delle forme ceramiche I. Ceramica fine romana nel bacino mediterraneo (medio e tardo Impero). Enciclopedia dell'Arte Antica Classica e Orientale. Roma, Istituto della Enciclopedia Italiana.

Bacaria, A. (1987): “Un lot de dérivées-des-sigillées paléochrétiennes à Iluro (Mataró, El Maresme, Espagne)". Documents d'Archéologie Méridionale 10: 123-128.

Bacaria, A. (1991): "Les imitations de D.S.P. sur le litoral catalan (Ve siècle apr. J.-C.)", en SFECAG, Actes du congrès de Cognac, pp. 353-363. Marsella, SFECAG.

Bacaria, A. (1992a): “Ceràmiques paleocristianes (DSP) del Museu de Palau de Plegamans (Vallès Occidental)". Arraona, revista d'Història 10: 79-84.

Bacaria, A. (1992b): "Les ceràmiques paleocristianes (dérivées-des-sigillées paléochrétiennes) del Penedès”, Miscel.lània Penedesenca XV: 213-232. Sant Sadurní d'Anoia, Institut d'Estudis Penedesencs.

Bacaria, A. (1993): "Tarraco i el comerç amb la Gàl. lia meridional durant el s. V d.C.: les importacions ceràmiques". Butlletí Arqueològic època V(15), pp. 339-345. Tarragona, Reial Societat Arqueològica Tarraconense.

Barrasetas, E. y Járrega, R. (1997): "La ceràmica trobada al jaciment de la Solana (Cubelles, Garraf)", en Contextos ceràmics d'època romana tardana $i$ de l'Alta Edat Mitjana (segles IV-X). Taula Rodona. Arqueomediterrània 2, pp. 131-152. Barcelona, Universitat de Barcelona.

Bernal, D. (1993): “Lucernae Tarraconenses: las lámparas romanas del Museu Nacional Arqueològic y del Museu i necrópolis Paleocristians", Butlletí Arqueolòic època V(15), pp. 59-298. Tarragona, Reial Societat Arqueològica Tarraconense.

Berni, P. (1997): Las ánforas de aceite de la Bética y su presencia en la Cataluña romana. Col. Instrumenta 4. Barcelona, Universitat de Barcelona.

Bonifay, M. (1983): "Elements d'evolution des céramiques de l'Antiquité tardive à Marseille d'aprés les fouilles de la Bourse (1980-1981)". Revue d'Archéologie Narbonnaise XVI: 285-346.

Bonifay, M. (1986): “Observations sur les amphores tardives à Marseille d'après les fouilles de La Bourse 
(1980-1984)". Révue d'Archeólogie Narbonnaise XIX: 269-305.

Bonifay, M. (2004): Études sur la céramique romaine tardive d'Afrique. BAR International Series 1301. Oxford, Archaeopress.

Bonifay, M.; Brenot, CL.; Foy, D.; Pelletier, J.P.; Pieri, D. y Rigoir, Y. (1998): “Le mobilier de l'Antiquité Tardive”, en M. Bonifay, B. Carre e Y. Rigoir (eds.), Fouilles à Marseille. Les mobiliers (Ier-VIIe siècles ap. J.-C.). Études Massaliettes 5: 355-419.

Bonifay, M. y Pieri, D. (1995): “Amphores du Ve au VIIe s. à Marseille: nouvelles données sur la typologie et le contenu“. Journal of Roman Archaeology 8: 94-120.

Bourgeois, A. (1970): “Céramique paléochrétienne de Barcelona (Museo de Historia de la Ciudad)". Melanges de la Casa de Velázquez 6: 53-77.

Cau, M.A. (1998): Cerámica tardorromana de cocina de las Islas Baleares: estudio arqueométrico. Barcelona, Universitat Autònoma de Barcelona.

Carignani, A.; Ciotola, A.; Pacetti, F. y Panella, C. (1986): "Roma. Il contesto del tempio della Magna Mater sul Palatino", en A. Giardina (ed.), Società romana e impero tardoantico, vol. III, pp. 27-43. Bari, Laterza.

Casas, J. y Soler V. (2003): La villa de Tolegassos. Una explotación agrícola de época romana en el territorio de Ampurias. BAR International Series 1101. Oxford, John and Erica Hedges.

Castanyer, P. y Tremoleda, J. (1999): La vil la romana de Vilauba. Un exemple de l'ocupació i explotació romana del territori a la comarca del Pla de l'Estany. Banyoles, Ajuntament de Porqueres y Centre d'Estudis Comarcals de Banyoles.

Cela, X. y Revilla, V. (2004): La transició del municipium d'Iluro a Alarona (Mataró). Cultura material i transformacions d'un espai urbà entre els segles Vi VI d.C. Laietania 15. Mataró, Patronat Municipal de Cultura.

Cerdà, J.A.; García, J.; Martí, C.; Pujol, J.; Pera, J. y Revilla, V. (1997): El cardo maximus de la ciutat romana d'Iluro (Hispania Tarraconensis). Laietania 10 (2 vols). Mataró, Patronat Municipal de Cultura.

Clariana, J.F. y Járrega, R. (1994): "Estudi de la fase Baix Imperial de la vil.la romana de Torre Llauder (Mataró, el Maresme). Les ceràmiques". Laietània 9: 253-289.

Coll, J.M.; Roig, J. y Molina, J.A. (1997a): “Las producciones cerámicas de época visigoda en la Catalunya central (ss. V-VII): algunas consideraciones técnicas y morfológicas", en La céramique médievale en Méditerranée. Actes du VIe Congrès de l'AIECM 2, pp. 193-197. Aix-en-Provence, Narrations.

Coll, J.M., Roig, J. y Molina, J.A. (1997b): "Contextos ceràmics de l'antiguitat tardana del Vallès", en Contextos ceràmics d'època romana tardana $i$ de l'Alta Edat Mitjana (segles IV-X). Taula Rodona. Arqueomediterrània 2: 37-57. Barcelona, Universitat de Barcelona.

Comas, M. y Padrós, P. (1997): "Un context ceràmic del segle VI a Baetulo”, en Contextos ceràmics d'època romana tardana $i$ de l'alta edat mitjana (segles IV-X). Taula Rodonda. Arqueomediterrània 2: 121-130. Barcelona, Universitat de Barcelona.

Del Amo, M.D. (1979): Estudio crítico de la necrópolis paleocristiana de Tarragona, Tarragona, Instituto de Estudios Tarraconenses "Ramón Berenguer IV". Tarragona, Diputación de Tarragona.

Del Amo, M.D. (1981): Estudio crítico de la necrópolis paleocristiana de Tarragona. Ilustraciones. Tarragona, Instituto de Estudios Tarraconenses "Ramón Berenguer IV", Diputación de Tarragona.

Enrich, J.; Enrich, J. y Pedraza, L. (1995): Vilaclara de Castellfollit del Boix (el Bages). Un assentament rural de l'antiguitat tardana. Igualada, Arqueoanoia Edicions.

Fabião, C. (2008): "Las ánforas de Lusitania", en D. Bernal y A. Ribera (eds.), Cerámicas hispanorromanas. Un estado de la cuestión: 725-745. Cádiz, Universidad de Cádiz.

Fulford, M.G. y Peacock, D.P.S. (1984): Excavations at Carthage: The British Mission, vol. I.2. The Avenue du Président Habib Bourguiba. Salammbo. Sheffield, University of Sheffield.

García Moreno, L.A. (1972): “Colonias de comerciantes orientales en la Península Ibérica durante la Antigüedad Tardía“. Archivo Español de Arqueología 50-51: 311-321.

García Vargas, Enrique. A. (2011): “Oriental trade in the Iberian Peninsula during Late Antiquity (4th7th cen-turies AD). An archaeological perspective". New Perspectives on Late Antiquity. Cambridge Scholars Publishing, Cambridge: 76-117.

García, G; Moro, A. y Tuset, F. (2009): La seu episcopal d'Ėgara. Arqueologia d'un conjunt cristià del segle IV al IX. Sèrie Documenta 8. Tarragona, Institut Català d'Arqueologia Clàssica.

García, I. y Rosselló, M. (1992): "Las ánforas tardorromanas de Punta de l'Illa de Cullera“. SIP, serie de Trabajos Varios 89, pp. 639-661. 
Guitart, J. (1970): "Excavaciones en la zona Sudeste de la villa romana de Sentromà (Tiana)". Pyrenae 6: 111-165.

Hayes, J.W. (1972): Late Roman Pottery. Londres, The British School at Rome.

Hayes, J.W. (1980): Supplement to Late Roman Pottery. Londres, The British Scool at Rome.

Izquierdo, P. (1997): “Barcino i el seu litoral: una aproximació a les comunicacions marítimes d'època antiga a la Laietània", en J. Roca (ed.), La formació del cinturó industrial de Barcelona, vol. 1, pp.1321. Barcelona, Institut Municipal d'Història de Barcelona y Proa.

Izquierdo, P. (2009): "Els ports del litoral tarraconense i el seu paper en el comerç del vi”, en M. Prevosti y A. Martín (eds.), El vi tarraconense i laietà, ahir i avui. Actes del simpòsium. Col. Documenta 7, pp. 179-191. Tarragona, Institut Català d'Arqueologia Clàssica.

Járrega, R. (1987): "Notas sobre la importación de cerámicas finas norteafricanas (sigillata clara $\mathrm{D}$ ) en la costa oriental de Hispania durante el siglo VI e inicios del VII d. de C.", en Actas del II Congreso de Arqueología Medieval Española, vol. II, pp. $337-$ 344. Madrid, Comunidad de Madrid.

Járrega, R. (1990a): "Una àmfora tardo-romana a la Conca de Tremp: dades sobre el comerç d'importació a 1'Antiguitat Tardana", en La romanització del Pirineu. 8è Col.loqui Internacional d'Arqueologia de Puigcerdà, pp. 131-136. Puigcerdà, Institut d'Estudis Ceretans.

Járrega, R. (1990b): “La ciudad de Tarraco y las repercusiones hispánicas de la rebelión de Magnencio: un problema histórico-arqueológico". Studia Historica. Historia Antigua VIII: 21-27.

Járrega, R. (1991): Cerámicas finas tardorromanas y del Mediterráneo oriental en España. Estado de la cuestión. Anejos de Archivo Español de Arqueología XI. Madrid, CSIC.

Járrega, R. (1993/2009): Poblamiento y economía en la costa Este de la Tarraconense en época tardorromana (siglos IV-VI). Tesis Doctoral, Universitat Autònoma de Barcelona, 1992 (publicación en microficha, 1993, y electrónica, 2009). Cerdanyola, Universitat Autònoma de Barcelona.

Járrega, R. (2000a): "Las cerámicas de importación en el nordeste de la Tarraconense durante los siglos VI y VII d. de J.C. Aproximación general", en $V R e$ unió d'Arqueologia Cristiana Hispànica, pp. $467-$ 483. Barcelona, Institut d'Estudis Catalans.

Járrega, R. (2000b): "La difusión de la producción anfórica bética en el área catalana durante el período bajoimperial. Las ánforas Dressel 23", en Congreso Internacional "ex Baetica amphorae" (Écija-Sevi1la, 1998), vol. II, pp. 605-620. Écija, Gráficas Sol.

Járrega, R. (2005a): “Ánforas tardorromanas halladas en las recientes excavaciones estratigráficas efectuadas en el subsuelo de la plaza del Rey en Barcelona”, en J.M. Gurt, J. Buxeda y M.A. Cau (eds.), $L R C W$ 1. Late Roman Coarse Wares, Cooking Wares and Amphorae in the Mediterranean: Archaeology and Archaeometry. BAR International Series 1340, pp. 151-163. Barcelona (2002), Oxford, Archaeopress.

Járrega, R. (2005b): "Los contextos cerámicos tardoantiguos del conjunto episcopal de Barcino", en L.A. García Moreno y S. Rascón (eds.), Guerra y rebelión en la Antigüedad Tardía. El siglo VII en España y su contexto mediterráneo. Actas de los IVy $V$ Encuentros Internacionales Hispania en la Antigüedad Tardia. Acta Antiqua Complutensia 5, pp. 231-251. Alcalá de Henares (1999 y 2000), Alcalá de Henares, Ayuntamiento de Alcalá de Henares.

Járrega, R. (2007a): "The end of Roman amphorae in coastal Hispania Tarraconensis (Catalonia) in the 6 th to 7 th centuries. Globular amphorae with a concave or umbilicated base", en M.M. Bonifay y J.C. Tréglia (eds.), LRCW 2. Late Roman Coarse Wares, Cooking Wares and Amphorae in the Mediterranean: Archaeology and Archaeometry. BAR International Series 1662 (I), pp. 211-218. Aixen-Provence-Marseille-Arles (2005), Oxford, Archaeopress.

Járrega, R. (2007b): “La vaixella fina i les àmfores”, en Francès, J. (coord.), Els Mallols. Un jaciment de la plana del Vallès, entre el neolitic i l'antiguitat tardana (Cerdanyola, Vallès Occidental). Excavacions Arqueològiques a Catalunya 17, pp. 119-137. Barcelona, Generalitat de Catalunya.

Járrega, R. (2007c): "Estudi de les ceràmiques fines i les àmfores tardoantigues de la Solana, Barcelona", en E. Barrasetas y R. Járrega (eds.), La Solana. Memòria de l'excavació arqueologica al jaciment. Excavacions Arqueològiques a Catalunya 18, pp. 83114. Barcelona, Generalitat de Catalunya.

Járrega, R. (2008): “La crisi del segle III a l'àrea compresa entre Tarraco i Saguntum. Aproximació a partir de les dades arqueològiques", en The countryside at the $3^{\text {rd }}$ century. From Septimius Severus to the Tetrarchy. Studies on the rural world in the Roman period 3, pp. 105-139. Girona-Banyoles, Universitat de Girona.

Járrega, R. y Clariana, J.F. (1994a): "Restes arquitectòniques d'època romana $\mathrm{i}$ un petit context 
estratigràfic tardo-antic trobats al carrer de les Espenyes (Mataró)", X Sessió d'Estudis Mataronins, pp. 33-46. Mataró, Museu Arxiu de Santa Maria y Patronat Municipal de Cultura.

Járrega, R. y Clariana, J.F. (1994b): “Ceràmica xipriota i egípcia-B tardo-romana a la comarca del Maresme", en III Reunió d'Arqueologia Cristiana Hispànica, pp. 333-337. Barcelona, Institut d'Estudis Catalans.

Járrega, R. y Clariana, J.F. (1996): "El jaciment arqueològic de Can Modolell (Cabrera de Mar, Maresme) durant l'Antiguitat Tardana. Estudi de les ceràmiques d'importació". Cypsela XI: 125-152.

Keay, S.J. (1984): The Late Roman Amphorae in the Western Mediterranean. A tipology and economic study: the Catalan evidence. BAR International Series 196 (2 vols.) Oxford, John and Erica Hedges.

Llinàs, J. (1997): "La excavación de la carretera de San Martín de Ampurias (Gerona): Un ejemplo de la evolución de los contextos cerámicos durante la Antigüedad Tardía en el litoral catalán". Archivo Español de Arqueología 70: 149-169.

Llovera, X. (ed.) (1997): Enclar. Transformacions d'un espai dominant, segles IV-XIX. Andorra, Govern d'Andorra.

López Rodríguez, J.R. (1985): Terra sigillata hispánica tardía decorada a molde de la Península Ibérica. Valladolid, Universidad de Valladolid.

López Mullor, A.; Fierro, X. y Caixal, A. (1997): “Ceràmica dels segles IV al X procedent de les comarques de Barcelona", en Contextos ceràmics d'època romana tardana i de l'Alta Edat Mitjana (segles IV-X). Taula Rodona. Arqueomediterrània 2, pp. 59-62. Barcelona, Universitat de Barcelona.

López Vilar, J. (2006): Les basíliques paleocristianes del suburbi occidental de Tarraco. El temple septentrional $i$ el complex martirial de Sant Fructuós. Sèrie Documenta 2. Tarragona, Institut Català d'Arqueologia Clàssica.

Mackensen, M. (1993): Die spätantiken sigillata- und Lampentöpfereien von El Mahrine (Nordtunesien). Münchner Beiträge zur Vor- und Frühgeschichte 50. Munich, C. H. Beck.

Macías, J.M. (1999): La ceràmica comuna tardoantiga a Tàrraco: anàlisi tipològica i històrica (segles $V$ VII). Tarragona, Museu Nacional Arqueológic.

Macías, J.M.; Menchón, J.J.; Puche, J.M. y Remolà, J.A. (1997): "Nous contextos ceràmics del segle IV i inicis del V en la província de Tarragona", en Contextos ceràmics d'època romana tardana $i$ de l'Alta Edat Mitjana (segles IV-X). Taula Rodona.
Arqueomediterrània, 2, pp. 153-177. Barcelona, Universitat de Barcelona.

Macías, J.M. y Remolà, J.A. (2000): “Tarraco visigoda: caracterización del material cerámico del siglo VII $\mathrm{dC}$, en V Reunión de Arqueología Cristiana Hispànica, pp. 485-497. Barcelona, Institut d'Estudis Catalans.

Méndez, R. y Ramallo, S. (1985): “Cerámicas tardías (siglos IV-VII) de Carthago Nova y su entorno", en Antigüedad y Cristianismo. Monografias sobre la Antigüedad tardía II, pp. 231-280. Murcia, Universidad de Murcia.

Mezquíriz, M.A. (1961): Terra Sigillata Hispánica. Valencia, Domench.

Murialdo, G. (1996): "Anfore tardoantiche nel Finale (VI-VII secolo)”. Rivista di Studi Liguri 59-60: 213-246.

Murialdo, G. (2001a): "Le anfore tra età tardoantica e protobizantina (V-VII secolo)", en D. Gandolfi (a cura di), La ceramica e i materiali di età romana. Classi, produzioni, commerci e consumi, pp. 395-406. Bordighera, Istituto Internazionale di di Studi Liguri.

Murialdo, G. (2001b): "Le anfore di trasporto", en T. Manoni, y G. Murialdo (a cura di), S. Antonino, un insediamento fortificato nella Liguria bizantina, pp. 255-296. Bordighera, Istituto Internazionale di di Studi Liguri.

Murialdo, G. (2001c): “I rapporti economici con l'area mediterranea e padana", en T. Manoni y G. Murialdo (a cura di), S. Antonino, un insediamento fortificato nella Liguria bizantina, pp. 301-307. Bordighera, Istituto Internazionale di di Studi Liguri.

Nieto, F.J. (1984): "Algunos datos sobre las importaciones de cerámica "Phocaean Red Slip" en la Península Ibérica", en Papers in Iberian Archaeology. BAR International Series 193, vol. II, pp. 540-551. Oxford, Archaeopress.

Nieto, F.J. (1993): El edificio " $A$ " de la Ciudadela de Roses (la terra sigillata africana). Girona, Centre d'Investigacions Arqueològiques de Girona.

Nolla, J.M. (1984): "Excavaciones recientes en la Ciudadela de Roses: el edificio bajo-imperial". Papers in Iberian Archaeology. BAR International Series 193, pp. 430-459. Oxford, Archaeopress.

Nolla, J.M. (1993): “Ampurias en la Antigüedad tardía. Una nueva perspectiva”. Archivo Español de Arqueología 66: 207-224.

Nolla, J.M. y Casas, J. (1997): "Material ceràmic del Puig de les Muralles (Puig Rom, Roses)", en Contextos ceràmics d'època romana tardana $i$ de l'alta edat mitjana (segles $I V-X)$. Arqueomediterrània 2: 7-19. 
Nolla, J.M. y Puertas, C. (1988): “Ceràmiques africanes i materials d'importació baix-imperial del jaciment del Camp de la Gruta (Torroella de Montgrí, Baix Empordà)". Estudis sobre temes del Baix Empordà 7: 29-77.

Nolla, J.M. y Sagrera, J. (1995): Ciuitatis Impuritanae coementeria. Les necròpolis tardanes de la Neàpolis. Estudi General 15. Girona, Universitat de Girona.

Palol, P. de (2004): El "castrum" del Puig de les Muralles de Puig Rom (Roses, Alt Empordà). Girona, Museu d'Arqueologia de Catalunya en Girona.

Parker, A. J. (1992): Ancient Shipwrecks of the Mediterranean \& the Roman Provinces. BAR International Series 580, Oxford, Archaeopress.

Paroli, L.; Citter, C.; Pellecuer, C. y Péne, J.M. (1996): "Commerci nel Mediterraneo occidentale nell'Alto Medioevo", en G.P. Brogiolo (ed.), Early Medieval Town in Western Mediterranean. Documenti di Archeologia 10: 121-142.

Pascual, R. (1963): "Las ánforas de la Plaza del Rey". Ampurias 25: 224-234.

Pascual, J., Ribera, A. y Rosselló, M. (2003): “Cerámicas de la ciudad de Valencia entre la época visigoda y omeya (siglos VI-X)", en L. Caballero, P. Mateos y M. Retuerce (eds.), Cerámicas tardorromanas y altomedievales en la Península Ibérica: ruptura y continuidad. Anejos de Archivo Español de Arqueología XXVIII, pp. 67-117. Madrid, CSIC.

Pavolini, C. (1986): "La circolazione delle lucerne in terra sigillata africana, en A. Giardina (ed.), Società romana e impero tardoantico vol. III, 241-250. Bari, Laterza.

Pérez Martín, W. (2007): Troballes arqueològiques al litoral tarragoní. Dotze anys d'arqueologia subaquàtica (1968-1990). Tarragona, Centre d'Estudis Marítims i Activitats del Port de Tarragona.

Piñol, L. (1995): "Els nivells tardo-romans i visigòtics del carrer Merceria, 11. El canvi funcional de les estructures alto-imperials de la part alta de Tarragona". Butlletí Arqueolòic, època V(17): 179-227.

Pociña, C.A. y Remolà, J.A. (2001): "Nuevas aportaciones al conocimiento del puerto de Tarraco (Hispania Tarraconensis)". Saguntum 33: 85-95.

Py, M.; Adroher, A.M. y Raynaud, C. (1993): DICOCER. Dictionaire des Céramiques Antiques (VIIème s. av.n.è.- VIIème s. d.n.è.) en Mediterranée nord-occidentale (Provence, Languedoc, Ampurdan). Lattara 6. Lattes, Association pour la recherche archéologique en Languedoc oriental.

Quaresma, J.C. (2008): "Le type Hayes 91 A et B: problématique de sa production au sein de la sigillée africaine D", Societé Française d'Étude de la Cèramique Antique en Gaule, Actes du Congrès de l'Escala-Ampurias: 495-502. L'Escala-Ampurias (2008), Marsella, SFECAG.

Raimondo, C. (1998): "La ceramica comune del Bruttium nel VI-VII secolo", en J.W. Hayes y L. Saguì (eds.), Ceramica in Italia: VI-VII secolo, vol. I, pp. 531-548. Florencia, All'Insegna del Giglio.

Ramallo, S.; Ruíz, E. y BerrocaL, M.C. (1997): “Un contexto del primer cuarto del siglo VII en Cartagena", en Contextos ceràmics d'època romana tardana i de l'alta edat mitjana (segles $I V-X)$. Arqueomediterrània 2: 203-228.

Remolà, J.A. (2000): Las ánforas tardo-antiguas en Tarraco (Hispania Tarraconensis). Col. Instrumenta 7. Barcelona, Institut Català d'Arqueologia Clàssica.

Remolà, J.A y Pociña, C.A. (2005): "La "font dels lleons", en P. Sada, E. Ramón y J.A. Remolà (eds.), Tarraco i l'aigua, pp. 53-66. Tarragona, Museu Nacional Arqueològic de Tarragona.

Remolà, J.A. y Uscatescu, A. (1998): "El comercio de ánforas orientales en Tarraco (siglos V-VII d.C.)", en 2on Col.loqui Internacional d'Arqueologia romana. El vi a l'Antiguitat. Economia, producció $i$ comerç al Mediterrani occidental, pp. 553-562. Badalona, Museu de Badalona.

Revilla, V. (2003): Economia i poblament romà al curs inferior de l'Ebre. La villa de Casa Blanca (Tortosa). Tarragona, Diputación de Tarragona.

Reynolds, P. (1987): El yacimiento tardorromano de Lucentum (Benalua - Alicante: las cerámicas finas. Catálogo de fondos del Museo Arqueológico I. Alicante, Diputación Provincial de Alicante.

Reynolds, P. (1995): Trade in the Western Mediterranean, A.D. 400-700: The ceramic evidence. British Archaeological Reports 604. Oxford, Archaeopress.

Ribas, M. (1967): "Una necrópolis romana en la basílica de Santa María del Mar, de Barcelona”. Ampurias XXIX: 196-228.

Ribas, M. (1968): "Descubrimiento de una necrópolis romana en la basílica de Santa María del Mar". Cuadernos de Arqueología e Historia de la Ciudad XII: 4-32.

Ribas, M. (1977): Necrópolis romana en la basílica de Santa María del Mar de Barcelona. Barcelona, Museo de Historia de la Ciudad.

Rigoir, J. y Rigoir, Y. (1971): "Les derivées des sigillées paléochrétiennes en Espagne". Rivista di Studi Liguri 37: 33-68. 
Sada, P.; Ramón, E. y Remolà, J.A. (eds.) (2005): Tarraco i l'aigua. Tarragona, Museu Nacional Arqueològic de Tarragona.

Saguì, L. (1998): "Il deposito della Crypta Balbi: una testimonianza imprevedibile sulla Roma del VI secolo?", en J.W. Hayes y L. Saguì (eds.), Ceramica in Italia: VI-VII secolo, vol. I, pp. 305-330. Florencia, All'Insegna del Giglio.

Sánchez Real, J. (1971-72): “Los enterramientos romanos de la Via Augusta". Boletín Arqueológico 113120: $173-208$

Serra Vilaró, J. (1927): Excavaciones en la necrópolis romano-cristiana de Tarragona. Memorias de la Junta Superior de Excavaciones y Antigüedades 93. Madrid, Tipografía de Archivos Olózaga.

Serra Vilaró, J. (1929): Excavaciones en la necrópolis romano-cristiana de Tarragona. Memorias de la Junta Superior de Excavaciones y Antigüedades 104, Madrid, Tipografía de Archivos Olózaga.

Serra Vilaró, J. (1930): Excavaciones en la necrópolis romano-cristiana de Tarragona. Memorias de la Junta Superior de Excavaciones y Antigüedades 111, Madrid, Tipografía de Archivos Olózaga.

Staffa, A. (1998): "Le produzioni ceramiche in Abruzzo tra fine V e VII secolo", en J.W. Hayes y L. Saguì (eds.) Ceramica in Italia: VI-VII secolo, vol. I, pp. 437-480. Florencia, All'Insegna del Giglio.

Ted'a (1989): Un abocador del segle $V d$. C. en el Fòrum provincial de Tàrraco. Memòries d'excavació 2. Tarragona, Taller Escola d'Arqueologia.

Tortorella, S. (1987): "La ceramica africana. Un riesame della problematica”, en P. Lévêque y J.P. Morel (eds.), Céramiques hellénistiques et romaines II, pp. 279327. Aix-en-Provence, Besançon, Centre Camille Jullian e Centre de Recherches d'Histoire ancienne.

Tortorella, S. (1995): "La ceramica africana: un bilancio dell'ultimo decennio di ricerche", en P. Trousset (ed.), Productions et exportations africaines. Actualités archéologiques, pp. 79-102. Paris, CTHS.

Whitehouse, D; Barker, G.; Reece, R. y Reese, D. (1982): "The Schola Praeconum I: the coins, pottery, lamps and fauna". Papers of the British School at Rome 50: 53-101. 